\title{
Making Engineered 3D DNA Crystals Robust
}

Zhe Li ${ }^{1}$, Longfei Liu ${ }^{1}$, Mengxi Zheng ${ }^{1}$, Jiemin Zhao ${ }^{1}$, Nadrian C. Seeman ${ }^{2 *}$, Chengde Mao ${ }^{1 *}$ Correspondence to: ned.seeman@nyu.edu,mao@purdue.edu

\section{Supplementary Materials}

\section{This PDF file includes:}

Materials and Methods

Figures S1 to S39

Movies S1 


\section{Materials and Methods}

Oligonucleotides

All oligonucleotides were purchased from IDT and purified by $15 \%-20 \%$ denaturing PAGE. Their concentrations were quantified by UV absorbance at $260 \mathrm{~nm}$.

DNA strands:

$\mathrm{s} \Delta^{3 \mathrm{~T}}$-L:

5'-CGGTATTCACCACGATGCGGTATTCACCACGATGCGGTATTCACCA CGATG-3'

$\mathrm{s} \Delta^{3 \mathrm{~T}}$-M: $\quad$ 5'-CAGCAGCCTGAATACCGCATCGTGGACAGCG-3'

$\mathrm{s} \Delta^{3 \mathrm{~T}}$-S: $\quad 5^{\prime}$-TGCGCTGTGGCTGC-3'

$\mathrm{s} \Delta^{4 \mathrm{~T}}$-L: $\quad$ ' '-CGGTATTCACCACGATGCGGTATTCACCACGATGCGGTATTCACCA CGATG-3'

$\mathrm{s} \Delta^{4 \mathrm{~T}}$-M: $\quad$ '-GAAAAACACTGCCTGAATACCGCATCGTGGACTGACTCAAAA-3'

$\mathrm{s} \Delta^{4 \mathrm{~T}}$-S: $\quad$ 5'-TCTTTTGAGTCAGTGGCAGTGTTTT-3'

$\mathrm{s} \Delta^{8 \mathrm{~T}}$-L: 5 '-CGGTCAGTAATTCACCACGAGCTAGATGCGGTCAGTAATTCACCAC GAGCTAGATGCGGTCAGTAATTCACCACGAGCTAGATG-3'

$\mathrm{s} \Delta^{8 \mathrm{~T}}$-L-6H7: 5'-GCTATGGGTGGTCTGGTTGGGATTGGCCCCGGGAGCTGGCTTTCGG TCAGTAATTCACCACGAGCTAGATGCGGTCAGTAATTCACCACGAGCT AGATGCGGTCAGTAATTCACCACGAGCTAGATG-3'

$\mathrm{s} \Delta^{8 \mathrm{~T}} \mathrm{-M}: \quad$ 5'-GAGGAGCAAACTTCTAACAGCATACTGCCTGAATTACTGACCGCAT CTAGCTCGTGGACTGATCGACCTCCTTGAAAGACAGAG-3'

$\mathrm{s} \Delta^{8 \mathrm{~T}}$-S: $\quad 5$ ' - CTCCTCTGTCTTTCAAGGAGGTCGATCAGTGGCAGTATGCTGTTAG AAGTTTGCTC-3'

$\mathrm{a} \Delta^{4 \mathrm{~T}}$-L: $\quad$ ' '-GTAATCGCACCGTCAACTATTGGTCACCTGAACGAGTTCTCCACCA AGATC-3'

a $\Delta^{4 \mathrm{~T}}$-L-6H7: 5'-GCTATGGGTGGTCTGGTTGGGATTGGCCCCGGGAGCTGGCTGTAAT CGCACCGTCAACTATTGGTCACCTGAACGAGTTCTCCACCAAGATC-3'

$\mathrm{a} \Delta^{4 \mathrm{~T}}$-M1: 5'-ACAAAACACTGCCTGCGATTACGATCTTGGACGAAGCGTCTG-3'

$\mathrm{a} \Delta^{4 \mathrm{~T}}$-M2: 5'-GACAGTGACAGCCTGACCAATAGTTGACGGACTGACTCAAAA-3'

a $\Delta^{4 \mathrm{~T}}$-M3: 5 '-GGTGCAAACGACCTGGAGAACTCGTTCAGGACCTACTGCTAC-3'

$\mathrm{a} \Delta^{4 \mathrm{~T}}$-S1: $\quad$ 5'-GTCAGACGCTTCGT GGTCGTTTGCA-3'

a $\Delta^{4 \mathrm{~T}}$-S2: $\quad$ ' '-TCTTTTGAGTCAGTGGCAGTGTTTT-3'

$\mathrm{a} \Delta{ }^{4 \mathrm{~T}}$-S3: $\quad$ 5'-CCGTAGCAGTAGGTGGCTGTCACTG-3'

DNA Motifs:

$\mathrm{s} \Delta^{3 \mathrm{~T}}$ :

$\mathrm{s} \Delta^{4 \mathrm{~T}}$ :

$\mathrm{s} \Delta^{8 \mathrm{~T}}$ :

$\mathrm{s} \Delta^{3 \mathrm{~T}}-\mathrm{L}+\mathrm{s} \Delta^{3 \mathrm{~T}}-\mathrm{M}+\mathrm{s} \Delta^{3 \mathrm{~T}}-\mathrm{S}(1: 3: 3)$

$\mathrm{s} \Delta^{4 \mathrm{~T}}-\mathrm{L}+\mathrm{s} \Delta^{4 \mathrm{~T}}-\mathrm{M}+\mathrm{s} \Delta^{4 \mathrm{~T}}-\mathrm{S}(1: 3: 3)$

$\mathrm{s} \Delta^{8 \mathrm{~T}}-\mathrm{L}+\mathrm{s} \Delta^{8 \mathrm{~T}}-\mathrm{M}+\mathrm{s} \Delta^{8 \mathrm{~T}}-\mathrm{S}(1: 3: 3)$

$\mathrm{s} \Delta^{8 \mathrm{~T}}-6 \mathrm{H} 7$ :

$\mathrm{s} \Delta^{8 \mathrm{~T}}-\mathrm{L}-6 \mathrm{H} 7+\mathrm{s} \Delta^{8 \mathrm{~T}}-\mathrm{M}+\mathrm{s} \Delta^{8 \mathrm{~T}}-\mathrm{S}(1: 3: 3)$

$\mathrm{a} \Delta^{4 \mathrm{~T}}:$

$\mathrm{a} \Delta^{4 \mathrm{~T}}-\mathrm{L}+\mathrm{a} \Delta^{4 \mathrm{~T}}-\mathrm{M} 1+\mathrm{a} \Delta^{4 \mathrm{~T}}-\mathrm{M} 2+\mathrm{a} \Delta^{4 \mathrm{~T}}-\mathrm{M} 3+\mathrm{a} \Delta^{4 \mathrm{~T}}-\mathrm{S} 1+\mathrm{a} \Delta^{4 \mathrm{~T}}-\mathrm{S} 2+\mathrm{a} \Delta^{4 \mathrm{~T}}-\mathrm{S} 3$

$\mathrm{a} \Delta^{4 \mathrm{~T}}-6 \mathrm{H} 7:$

$(1: 1: 1: 1: 1: 1: 1)$

$\mathrm{a} \Delta^{4 \mathrm{~T}}-\mathrm{L}-6 \mathrm{H} 7+\mathrm{a} \Delta^{4 \mathrm{~T}}-\mathrm{M} 1+\mathrm{a} \Delta^{4 \mathrm{~T}}-\mathrm{M} 2+\mathrm{a} \Delta^{4 \mathrm{~T}}-\mathrm{M} 3+\mathrm{a} \Delta^{4 \mathrm{~T}}-\mathrm{S} 1+\mathrm{a} \Delta^{4 \mathrm{~T}}-\mathrm{S} 2+\mathrm{a} \Delta^{4 \mathrm{~T}}-\mathrm{S} 3$

$(1: 1: 1: 1: 1: 1: 1)$ 
$\underline{\text { Buffers }}$

TBE:

TAE:

$89 \mathrm{mM}$ Tris base, $89 \mathrm{mM}$ boric acid, 2 mM EDTA, pH 8.0.

$1 \times$ TAE contains $40 \mathrm{mM}$ Tris base, $20 \mathrm{mM}$ acetic acid, $2 \mathrm{mM}$ EDTA, $\mathrm{pH}$

8.0. For $N \times$ TAE, the buffer was prepared as concentrated or diluted $N$ times.

TAE $/ \mathrm{Mg}^{2+}: \quad 1 \times \mathrm{TAE} / \mathrm{Mg}^{2+}$ contains $40 \mathrm{mM}$ Tris base, $20 \mathrm{mM}$ acetic acid, $2 \mathrm{mM}$ EDTA, $\mathrm{pH} 8.0$, and $12.5 \mathrm{mM}$ magnesium acetate. For $N \times \mathrm{TAE} / \mathrm{Mg}^{2+}$, the buffer was prepared as concentrated or diluted $N$ times.

Phosphate buffer: $\quad 0.1 \mathrm{M} \mathrm{KH}_{2} \mathrm{PO}_{4}$, $\mathrm{pH}$ was adjusted by $\mathrm{KOH}$ to 5 or 6

PBS:

$154 \mathrm{mM} \mathrm{NaCl}, 5.6 \mathrm{mM} \mathrm{Na}_{2} \mathrm{HPO}_{4}, 1 \mathrm{mM} \mathrm{KH}_{2} \mathrm{PO}_{4}, \mathrm{pH} 7.4$

5'-phosphorylation of DNA

Purified DNA strands were phosphorylated by T4 polynucleotide kinase (New England Biolabs, Inc., NEB) overnight ( $5 \mu \mathrm{L}$ kinase (50 units) for every $4 \mathrm{nmol}$ of DNA) in T4 DNA ligase reaction buffer (New England Biolabs, Inc., NEB). On the second day, the mixture was phenol extracted to remove kinase. Phosphorylated DNA strands were then ethanol precipitated from the solution. The pellet was washed and redissolved in water. Then they were desalted by home-made spin columns of G25 matrix (Illustra, Sephadex G-25 Superfine DNA Grade).

\section{Crystallization of DNA triangle crystals}

DNA motifs were mixed by corresponding strands in TAE $/ \mathrm{Mg}^{2+}$ buffer. The strands and their molar ratio are listed in DNA Motifs, and motif, buffer concentration for each design are listed below. The DNA solution was slowly cooled from $95{ }^{\circ} \mathrm{C}$ to $22^{\circ} \mathrm{C}$ in 2 hours. Then $5 \mu \mathrm{L}$ of the solution was incubated against $600 \mu \mathrm{L}$ of reservoir buffer in a hanging-drop setup at $22^{\circ} \mathrm{C}$ for from 3 days to a week. Rhombohedral shape crystals of 50-200 $\mu \mathrm{m}$ size appeared in the drops. For the $\mathrm{s} \Delta^{8 \mathrm{~T}}$ crystal, $\mathrm{L}$ and $\mathrm{M}$ strands were first mixed and annealed from $95{ }^{\circ} \mathrm{C}$ to $22^{\circ} \mathrm{C}$ in 2 hours, and then the $3^{\text {rd }}$ strand was added to anneal from $50{ }^{\circ} \mathrm{C}$ to $22{ }^{\circ} \mathrm{C}$ in 2 hours, which can avoid the kinetic trap and increase assembly yield. For the same crystal design with and without aptamer, the same annealing protocol was applied.

$$
\begin{array}{ll}
\mathrm{s} \Delta^{3 \mathrm{~T}} \text { crystal: } & 2 \mu \mathrm{M} \text { motif in } 0.5 \times \mathrm{TAE} / \mathrm{Mg}^{2+}, \text { reservoir buffer: } 10 \times \mathrm{TAE} / \mathrm{Mg}^{2+} \\
\mathrm{s} \Delta^{4 \mathrm{~T}} \text { crystal: } & 2 \mu \mathrm{M} \text { motif in } 0.5 \times \mathrm{TAE} / \mathrm{Mg}^{2+} \text {, reservoir buffer: } 5 \times \mathrm{TAE} / \mathrm{Mg}^{2+} \\
\mathrm{s} \Delta^{8 \mathrm{~T}} \text { crystal: } & 2 \mu \mathrm{M} \text { motif in } 0.2 \times \mathrm{TAE} / \mathrm{Mg}^{2+}, \text { reservoir buffer: } 3 \times \mathrm{TAE} / \mathrm{Mg}^{2+} \\
\mathrm{a} \Delta^{4 \mathrm{~T}} \text { crystal: } & 2 \mu \mathrm{M} \text { motif in } 0.2 \times \mathrm{TAE} / \mathrm{Mg}^{2+} \text {, reservoir buffer: } 3 \times \mathrm{TAE} / \mathrm{Mg}^{2+}
\end{array}
$$

Ligation of DNA triangles in solution

DNA motifs were assembled by the same annealing protocol as in crystallization. To $10 \mu \mathrm{L}$ solution of DNA motifs, $1 \mu \mathrm{L}$ of $10 \mathrm{mM}$ ATP and $1 \mu \mathrm{L}$ of 400 units/ $\mu \mathrm{L}$ T4 DNA ligase (New England Biolabs, Inc., NEB) were added. The mixture was incubated at room temperature overnight.

Washing and buffer exchange of DNA triangle crystals

Unless specified otherwise, if the crystal was "transferred", the crystal was taken out by cryoloop, with minimal buffer, into another new drop. If the crystal was "washed", most of the original buffer was pipetted away from the crystal (leaving only $1 \sim 2 \mu \mathrm{L}$ ), and the new buffer was added to the crystal. The wash by transferring is supposed to be a better wash than drawing and 
adding solution, but requires more mechanical handling of crystal, which sometimes creates cracks. For the extensive wash, crystals were transferred for more than five times into clean buffers, followed by overnight incubation and three extra washes in the same buffer. For buffer exchange, the crystal was first transferred into $10 \mu \mathrm{L}$ of target buffer, and then washed three times by $10 \mu \mathrm{L}$ of target buffer.

\section{Ligation of DNA triangle crystals}

Crystals were washed twice by $5 \times \mathrm{TAE} / \mathrm{Mg}^{2+}$ buffer and then incubated overnight in the freshly prepared ligation mixture. The mixture contains $1 \mathrm{mM}$ ATP and 80 units/ $\mu \mathrm{L}$ T4 DNA ligase (New England Biolabs, Inc., NEB) in $5 \times \mathrm{TAE} / \mathrm{Mg}^{2+}$. After incubation, the crystals were transferred three times into $10 \mu \mathrm{L} 5 \times \mathrm{TAE} / \mathrm{Mg}^{2+}$ to wash off the ligase mixture, and then they were washed twice by $5 \times \mathrm{TAE} / \mathrm{Mg}^{2+}$. Crystals were finally stored in $5 \times \mathrm{TAE} / \mathrm{Mg}^{2+}$. For $\mathrm{s} \Delta^{8 \mathrm{~T}}$ crystals, all $5 \times \mathrm{TAE} / \mathrm{Mg}^{2+}$ were changed to $2.5 \times \mathrm{TAE} / \mathrm{Mg}^{2+}$.

\section{Denaturing PAGE}

Denaturing PAGE containing 20\% polyacrylamide (19:1 acrylamide/ bisacrylamide) and 8.3 M urea was run in Hoefer SE 600 electrophoresis unit at $600 \mathrm{~V}$ at $55^{\circ} \mathrm{C}$ in TBE. For sample preparation, ligated crystals from 5 crystal drops of $\mathrm{s} \Delta^{3 \mathrm{~T}}, \mathrm{~s} \Delta^{4 \mathrm{~T}}$ or $\mathrm{s} \Delta^{8 \mathrm{~T}}$ were transferred to $75 \mu \mathrm{L}$ of formamide. The crystals dissolved upon transferring. The solution was heated at $95{ }^{\circ} \mathrm{C}$ for $\sim 10$ min before loading into the denaturing gel.

\section{Native PAGE}

Native PAGE containing 6\% polyacrylamide (19:1 acrylamide/ bisacrylamide) was run in Hoefer SE 600 electrophoresis unit at $250 \mathrm{~V}$ at room temperature in $1 \times \mathrm{TAE} / \mathrm{Mg}^{2+}$ buffer. After electrophoresis, the gels were stained by stains-all (Sigma), destained and scanned on an office HP scanner.

\section{Rod model for DNA triangle crystals}

Rod models for DNA triangle crystals were built by 3ds Max software. All DNA duplex were represented by rods of $2 \mathrm{~nm}$ diameter, and the length of the rods was set as $3.4 \mathrm{~nm}$ for each helical turn of 10.5 base pairs, regardless of sequence and nicks. According to the design, the duplexes would extend along the three dimensions of DNA crystal. The sites of the connections and the angles were calculated from X-ray diffraction data in a previous publication ${ }^{5}$. For DNA motifs with the same inter junction length, the relative angles between duplexes were assumed to be the same. The models were presented with $2 \times 2 \times 2$ (single unit cell), $3 \times 3 \times 3$ and $5 \times 5 \times 5$ arrangement of DNA motifs.

\section{CanDo model for DNA triangle crystals}

Atomic models for DNA triangle crystals were predicted from finite element modeling framework CanDo. The DNA crystal unit cells were first drawn in Tiamat $^{1}$ and then used as input for the simulation. The Holliday junction angle was set as $60^{\circ}$ for the simulation, and random sequences were used. The finals structures were presented in a surface presentation by UCSF Chimera $^{2}$.

$\underline{\text { Size match between T4 DNA ligase and DNA crystal }}$ 
T4 DNA ligase has a molecular weight of $55.3 \mathrm{kD}$, and it contains 487 aa. The protein size was estimated from its molecular weight. The density of the protein was estimated as $1.4 \mathrm{~g} / \mathrm{cm}^{3}$ according to average protein density ${ }^{3}$. According to this, T4 DNA ligase was simplified as a sphere with a diameter of about $5.4 \mathrm{~nm}$. This sphere model was then used to compare with the rod models of DNA crystals. For comparisons of atomic structures, crystal structure of T4 DNA ligase with DNA substrate (PDB ID: 6dt1) ${ }^{4}$ was aligned with CanDo generated DNA triangle models in Pymol by the four nucleotides opposed to the nick.

\section{Optical and fluorescence microscope imaging}

Optical and fluorescence microscope images of the crystal drops were taken on microscope (Olympus, BX51) with an attached CCD camera. For fluorescence imaging, two different excitations of 330 385 nm and 460 490 nm were used.

\section{$\underline{\text { X-ray diffraction }}$}

Crystals were transferred into a drop containing artificial mother liquor supplemented with $30 \%$ glycerol. Then a crystal was picked by cryoloop and cryocooled by liquid nitrogen. Diffraction data were collected at $1.54 \AA$ on a Rigaku RU-H2R rotating anode X-ray machine at Purdue University (the detector distance was $200 \mathrm{~mm}$ ). All the data were indexed and refined using HKL $2000^{5}$ to determine the unit cell parameters.

Negative stain TEM imaging

Microcrystals of DNA $\mathrm{s} \Delta^{4 \mathrm{~T}}$ were obtained by mixing an equal volume of $2 \mu \mathrm{M}$ motif in $0.2 \times \mathrm{TAE} / \mathrm{Mg}^{2+}$ with $10 \times \mathrm{TAE} / \mathrm{Mg}^{2+}$, which was then incubated overnight at room temperature. Crushed DNA s $\Delta^{4 \mathrm{~T}}$ crystals were prepared by adding $5 \mu \mathrm{L} 5 \times \mathrm{TAE} / \mathrm{Mg}^{2+}$ to the crystal drop and crushing the crystals into small pieces by cryoloop under the microscope. $5 \mu \mathrm{L}$ of microcrystals or crushed crystals were then incubated on glow discharged TEM grid (Formvar/Carbon 400 mesh $\mathrm{Cu}$ grid) for 10 15 mins for sufficient sample attachment. The grid was blotted by filter paper from the side and stained by $3 \mu \mathrm{L} 0.8 \%$ uranium formate. Then the grid was quickly blotted again and stained with another $3 \mu \mathrm{L} 0.8 \%$ uranium formate for $20 \mathrm{~s}$. The grid was finally blotted and dried in air. The grids were observed on FEI Tecnai T20 transmission electron microscope at Purdue microscope facility.

\section{AFM imaging}

AFM images are captured by MultiMode 8 (Bruker) using ScanAsyst-fluid mode with ScanAsyst-fluid + probes (Bruker) and ScanAsyst-air mode with ScanAsyst-air probes (Bruker). Parameters such as set-point and gains are automatically adjusted by software to optimize imaging conditions.

\section{Preparation of DNA crystals with complex architectures}

For crystal shell, a crystal was transferred out from the crystallization drop in $10 \mu \mathrm{L}$ $5 \times \mathrm{TAE} / \mathrm{Mg}^{2+}$, followed by three washes with $10 \mu \mathrm{L} 5 \times \mathrm{TAE} / \mathrm{Mg}^{2+}$. Most of the buffer was drawn from the crystal drop under the microscope. Then $5 \mu \mathrm{L}$ ligation mixture containing $1 \mathrm{mM}$ ATP and 80 units $/ \mu \mathrm{L}$ T4 DNA ligase in $5 \times \mathrm{TAE} / \mathrm{Mg}^{2+}$ was added to the crystal. $6 \sim 8$ mins of ligation were applied depending on the size of the crystal. During ligation, the crystal was disturbed by cryoloop to float around in the drop to avoid the heterogeneity of the ligation depth in different orientations. The ligated crystal was transferred to $10 \mu \mathrm{L} 1 \times \mathrm{TAE} / 0.5 \mathrm{M} \mathrm{NaCl}$ to quench the 
ligation by high $\mathrm{Na}^{+}$concentration and to wash off the ligase. After transferred to another $10 \mu \mathrm{L}$ drop of $1 \times \mathrm{TAE} / 0.5 \mathrm{M} \mathrm{NaCl}$ to wash again, the crystal was transferred to $10 \mu \mathrm{L} 0.5 \times \mathrm{TAE} / \mathrm{Mg}^{2+}$. The interior of the crystal that was not ligated would dissociate and exit the crystal from crystal pores, leaving a crystal shell.

For yolk-shell, a crystal was washed by $5 \times \mathrm{TAE} / \mathrm{Mg}^{2+}$ and ligated in the ligation mixture for 10 mins. Then the ligated crystal was transferred three times into $10 \mu \mathrm{L} 0.5 \times \mathrm{TAE} / \mathrm{Mg}^{2+}$ and was washed three times by $10 \mu \mathrm{L} 0.5 \times \mathrm{TAE} / \mathrm{Mg}^{2+}$. The crystal was then transferred into $5 \mu \mathrm{L}$ drop of annealed crystal motifs for macroseeding. Because the crystal seed was ligated, it won't dissolve in the drop. Note crystal seeds with overnight ligation were found to be unsuitable for macroseeding. Multiple crystals were seeded from the same crystal seed, possibly because long time of ligation changed the surface property of the seed. After macroseeding, the outer shell was prepared in the same way as the crystal shell. For a clear shell away from the seed, only 3-4 mins of ligation was applied.

For matryoshka-doll architectures, crystal shell was washed three times in $0.5 \times \mathrm{TAE} / \mathrm{Mg}^{2+}$ and was used as a seed for macroseeding. After macroseeding, a new shell was prepared outside the original shell by 3-4 mins of ligation. After quenching and dissociation, the multiple shell crystal can be used as a new seed to prepare more shells.

$\underline{\text { Surface potential prediction of DNA and proteins }}$

The surface electrostatic potential of DNA and proteins used for entrapment were predicted by APBS-PDB2PQR web server (http://www.poissonboltzmann.org) 6 . For horseradish peroxidase (HRP), $\mathrm{pH}$ was set as 6; For green fluorescence protein (GFP) and GFP-deaminase, $\mathrm{pH}$ was set at 7.4. DNA duplex predicted at $\mathrm{pH} 6$, and $\mathrm{pH} 7.4$ both demonstrated strong negative surface potential as expected. His tags were not modeled in the calculation. All results were visualized in PyMOL molecular graphics systems.

Heterogeneous catalysis by HRP immobilized DNA crystal

Ligated DNA crystals were buffer exchanged to $0.1 \mathrm{M} \mathrm{KH}_{2} \mathrm{PO}_{4}, \mathrm{pH}$ 6, and were incubated with $\sim 20 \mathrm{mg} / \mathrm{mL}$ horseradish peroxidase (HRP) (Sigma) in the same buffer for a week at $4{ }^{\circ} \mathrm{C}$. Clear encapsulation of HRP can be observed in 2 days, with the crystals turning brown. The crystals were then used to catalyze the reaction between ABTS and peroxide. The crystal surface was blocked by polylysine to eliminate enzyme leakage by incubating in $5 \mu \mathrm{g} / \mathrm{mL}$ polylysine, 0.1 $\mathrm{M} \mathrm{KH}_{2} \mathrm{PO}_{4}$, $\mathrm{pH} 5$ for 1 hour, and then the crystal was extensively washed by $0.1 \mathrm{M} \mathrm{KH}_{2} \mathrm{PO}_{4}, \mathrm{pH}$ 5. The substrate mixture contained $5 \mathrm{mg} / \mathrm{mL}$ ABTS and $0.01 \% \mathrm{H}_{2} \mathrm{O}_{2}$ in $0.1 \mathrm{M} \mathrm{KH}_{2} \mathrm{PO}_{4}, \mathrm{pH} 5$, and was freshly prepared on the same day. The catalysis reaction was performed either in $5 \mu \mathrm{L}$ drop for microscope observation or in $100 \mu \mathrm{L}$ solution for spectrophotometer measurement at $414 \mathrm{~nm}$. The crystal was transferred by cryoloop into the drop or the cuvette for reaction. For spectrophotometer measurement, the solution in the cuvette was gently pipetted to mix evenly before each data point was taken. The crystal became violet after catalysis and it could be observed and tracked by bare eyes. After each catalysis cycle, the crystal was taken out by pipet onto a slide and washed three times by $0.1 \mathrm{M} \mathrm{KH}_{2} \mathrm{PO}_{4}, \mathrm{pH} 5$.

Entrapment of His-tag Proteins in DNA Crystal

Ligated DNA $\mathrm{a} \Delta^{4 \mathrm{~T}}-6 \mathrm{H} 7$ and $\mathrm{s} \Delta^{8 \mathrm{~T}}-6 \mathrm{H} 7$ crystals were buffer exchanged to PBS buffer before protein entrapment. a $\Delta^{4 \mathrm{~T}}-6 \mathrm{H} 7$ was incubated at room temperature in $5 \mu \mathrm{L}$ of $3.7 \mu \mathrm{M}$ His tagged green fluorescence protein (GFP) (ThermoFisher Scientific) in PBS buffer. $\mathrm{s} \Delta^{8 \mathrm{~T}}-6 \mathrm{H} 7$ crystal was 
incubated at room temperature in $5 \mu \mathrm{L}$ of $3.7 \mu \mathrm{M}$ His tagged GFP-deaminase recombinant protein in PBS buffer. His tagged GFP-deaminase recombinant protein was a generous gift from Ninghai Gan of Zhao-qing Luo's lab at the department of biological science, Purdue University. All incubations were set in the dark until imaging. The encapsulation process was examined by fluorescence microscopy (OLYMPUS, BX51). In the same group of samples, the same exposure time was used for parallel comparison, and the exact time was specified in figure captions.

Staining of DNA crystal by fluorescent and colorimetric dyes

Ligated DNA crystals were buffer exchanged $0.2 \times \mathrm{TAE} / \mathrm{Mg}^{2+}$ and then incubated in $5 \mu \mathrm{L}$ of $0.2 \times \mathrm{TAE} / \mathrm{Mg}^{2+}$. The fluorescent dyes were used at $2 \mu \mathrm{M}(1 \times)$ or $20 \mu \mathrm{M}(10 \times)$ concentration, and $2 \mu \mathrm{L}$ of dye was added each time. The colorimetric dyes were used at $100 \mu \mathrm{M}$, and $0.5 \mu \mathrm{L}$ dye was added each time.

\section{REFERENCES}

1. Sean Williams, Kyle Lund, Chenxiang Lin, Peter Wonka, Stuart Lindsay \& Hao Yan. "Tiamat: A Three-Dimensional Editing Tool for Complex DNA Structures.” DNA Computing, 90-101 (2009), Ashish Goel, Friedrich C. Simmel, Petr Sosík, Eds., Springer (Berlin).

2. Eric F. Pettersen, Thomas D. Goddard, Conrad C. Huang, Gregory S. Couch, Daniel M. Greenblatt, Elaine C. Meng \& Thomas E. Ferrin. UCSF Chimera-A visualization system for exploratory research and analysis. J. Comput. Chem. 25, 1605-1612 (2004).

3. Hannes Fischer, Igor Polikarpov \& Aldo F. Craievich. Average protein density is a molecularweight-dependent function. Protein Sci. 13, 2825-2828 (2004).

4. Ke Shi, Thomas E Bohl, Jeonghyun Park, Andrew Zasada, Shray Malik, Surajit Banerjee, Vincent Tran, Na Li, Zhiqi Yin, Fredy Kurniawan, Kayo Orellana \& Hideki Aihara. T4 DNA ligase structure reveals a prototypical ATP-dependent ligase with a unique mode of sliding clamp interaction. Nucleic Acids Res. 46, 10474-10488 (2018).

5. Zbyszek Otwinowski, Wladek Minor. "Processing of X-ray Diffraction Data Collected in Oscillation Mode." Methods in Enzymology, 276, 307-326 (1997), Macromolecular Crystallography, part A, Charles W. Carter, Jr., Eds., Academic Press (New York).

6. Elizabeth Jurrus, Dave Engel, Keith Star, Kyle Monson, Juan Brandi, Lisa E. Felberg, David H. Brookes, Leighton Wilson, Jiahui Chen, Karina Liles, Minju Chun, Peter Li, David W. Gohara, Todd Dolinsky, Robert Konecny, David R. Koes, Jens Erik Nielsen, Teresa Head Gordon, Weihua Geng, Robert Krasny, Guo Wei Wei, Michael J. Holst, J. Andrew McCammon \& Nathan A. Baker. Improvements to the APBS biomolecular solvation software suite. Protein Sci. 27, $112-128$ (2018). 
Fig. S1. Scheme of DNA tensegrity triangles with sequence
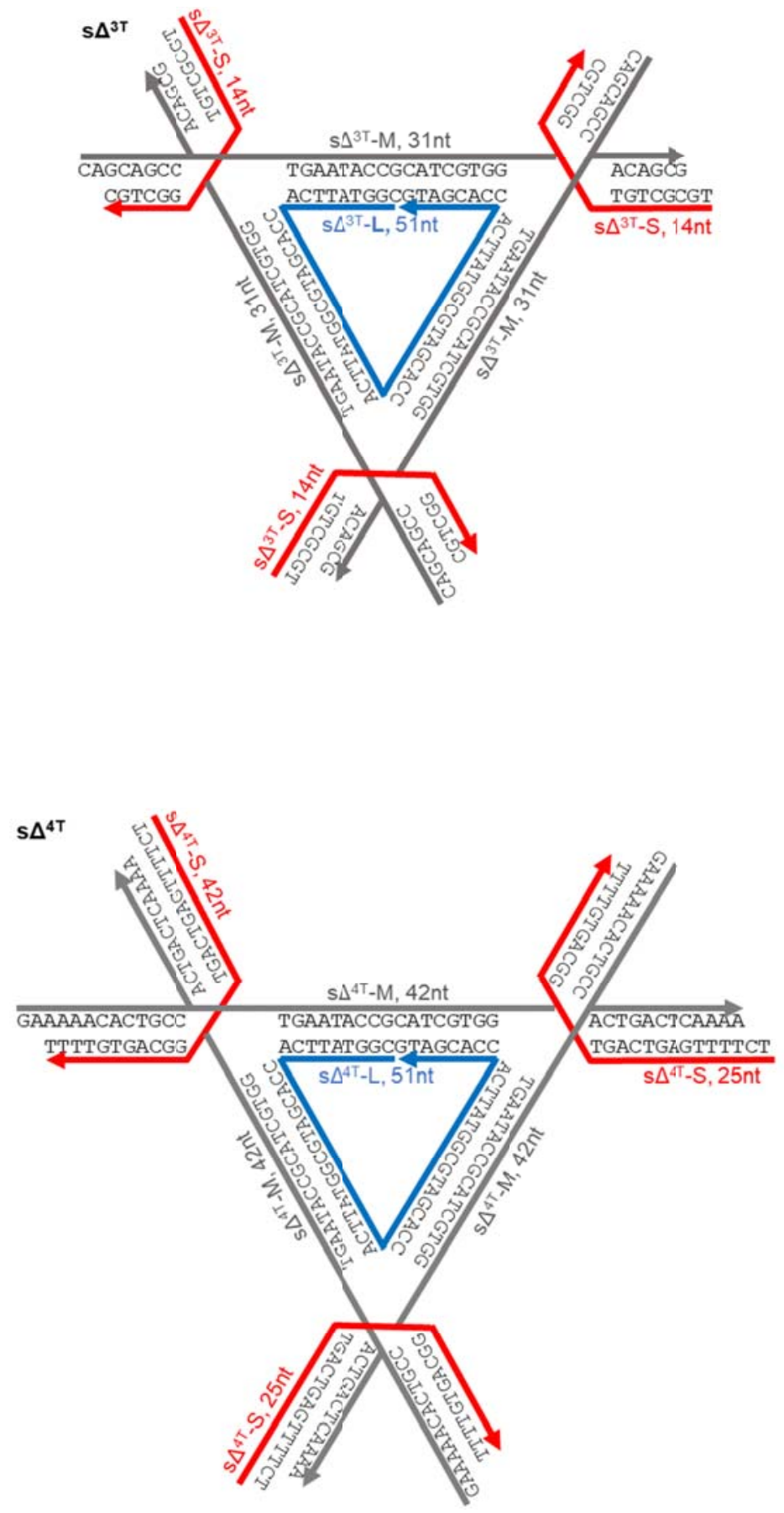

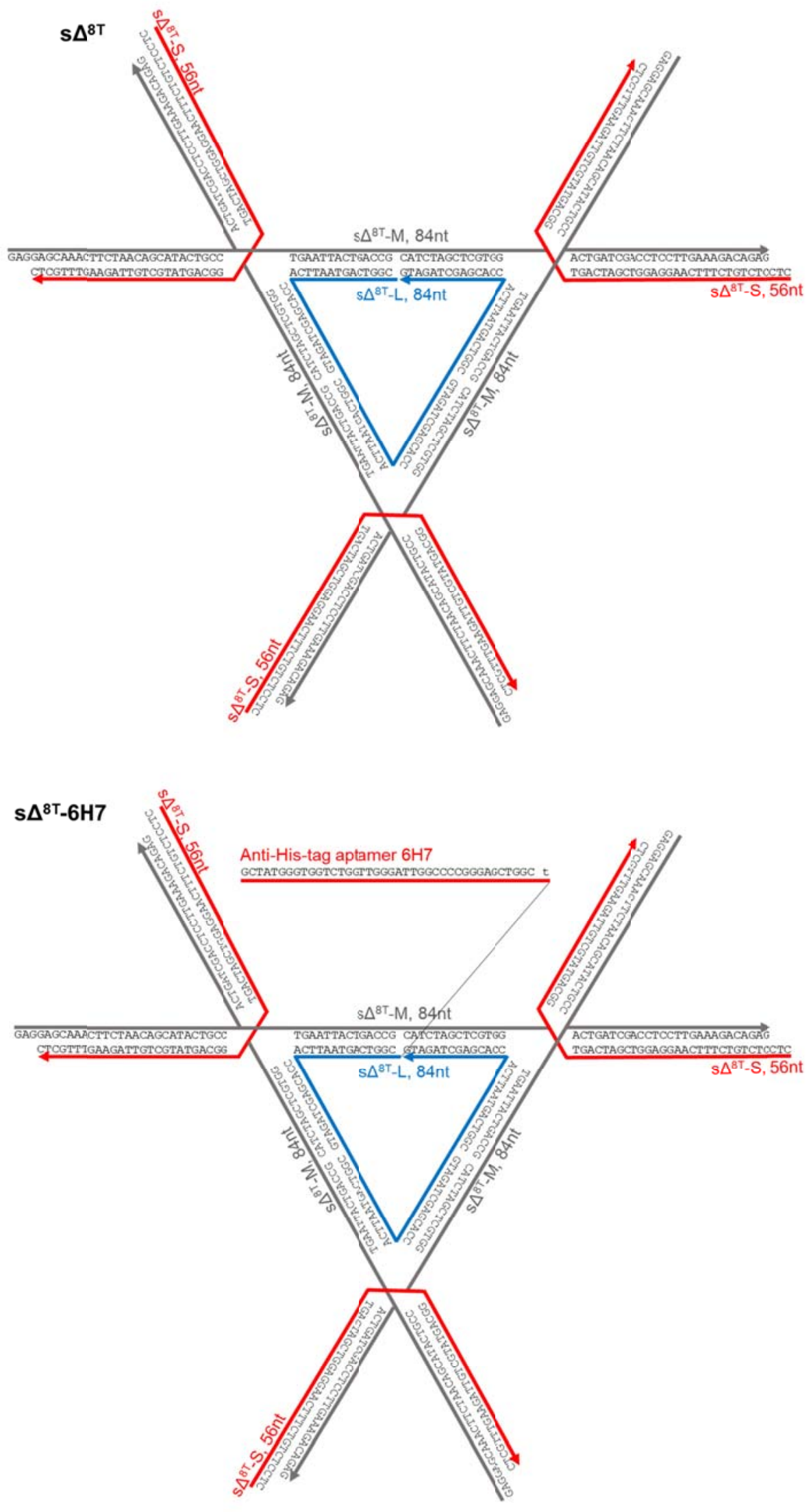

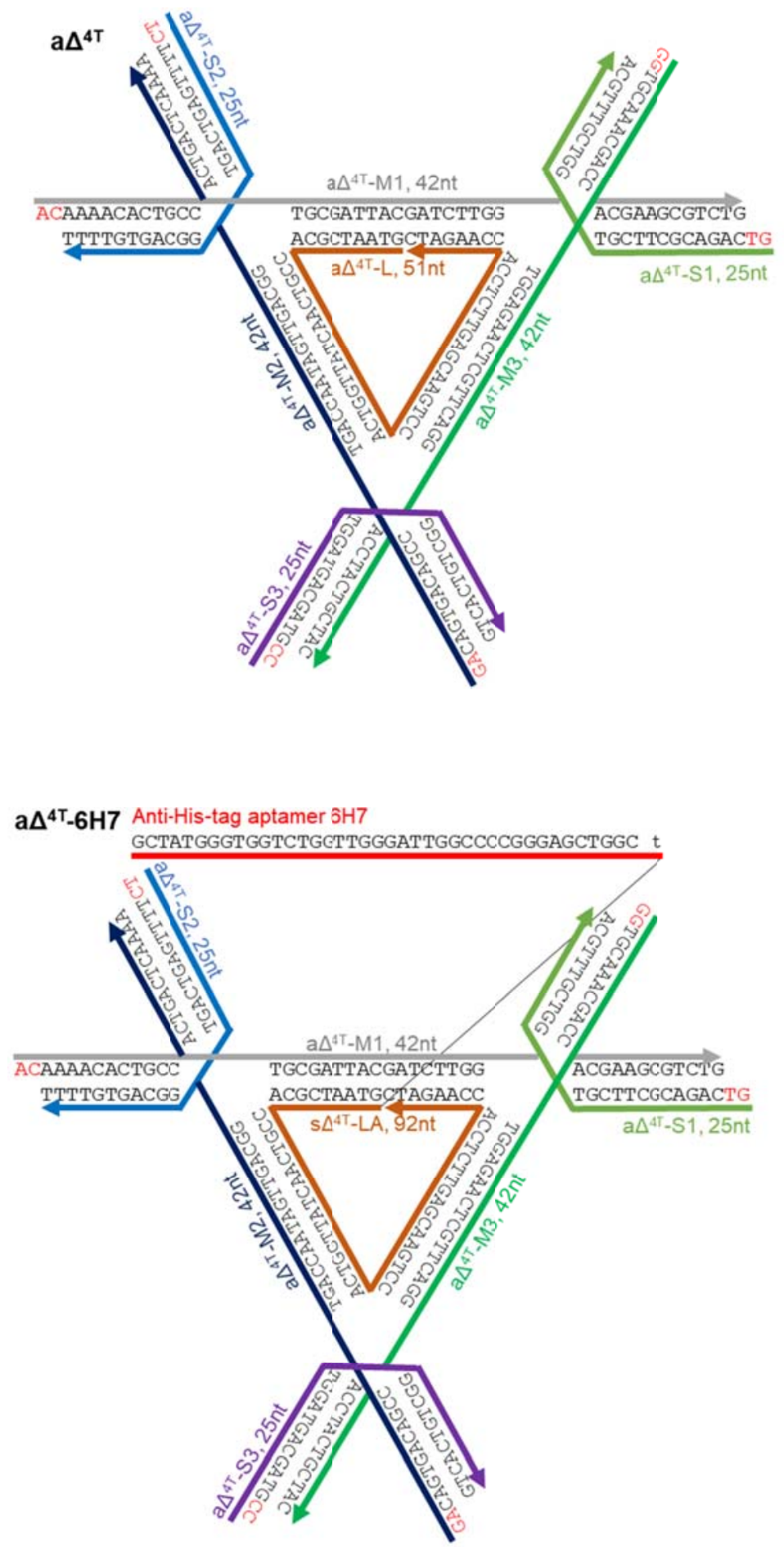


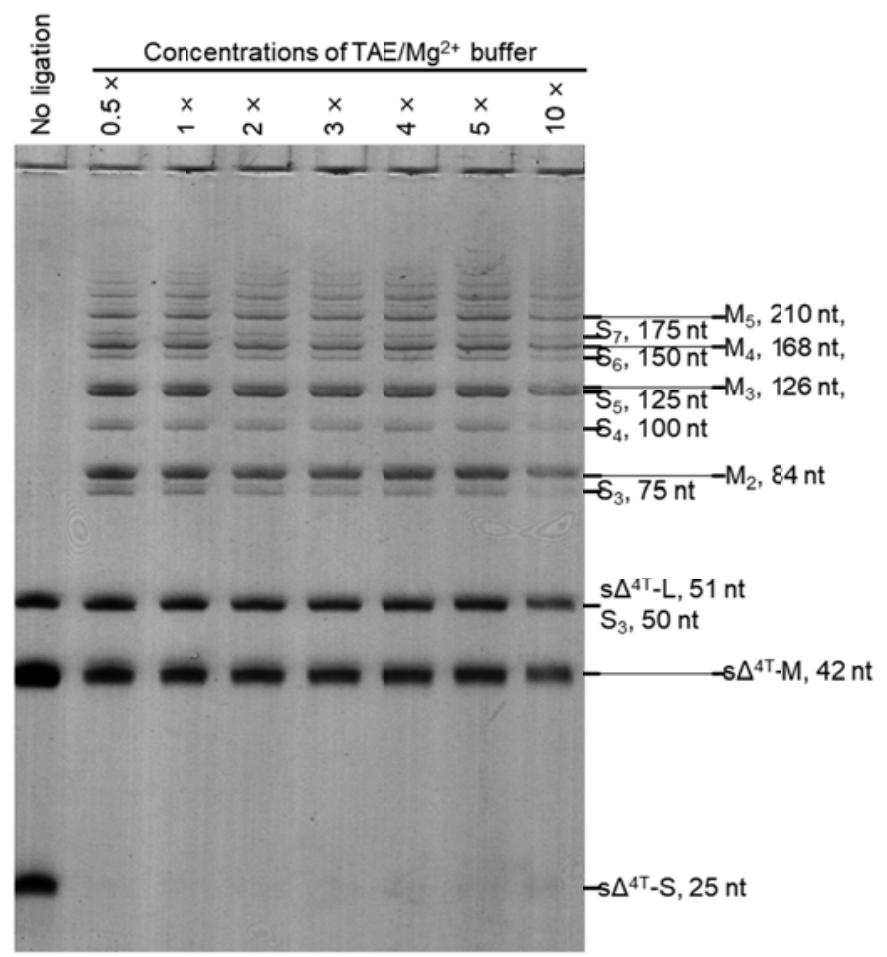

Fig. S2. T4 DNA ligase activity in different concentrations of TAE/Mg ${ }^{2+}$ buffer. Assembled DNA $\mathrm{s} \Delta^{4 \mathrm{~T}}$ motifs were used to test the efficiency of ligation in solution, while buffer concentration varied in the range of $0.5 \times$ to $10 \times \mathrm{TAE} / \mathrm{Mg}^{2+}$. The last lane has slightly less sample than other lanes. From 20\% denaturing PAGE analysis, DNA strands were ligated with similar, high yield in this range of buffer concentration. 


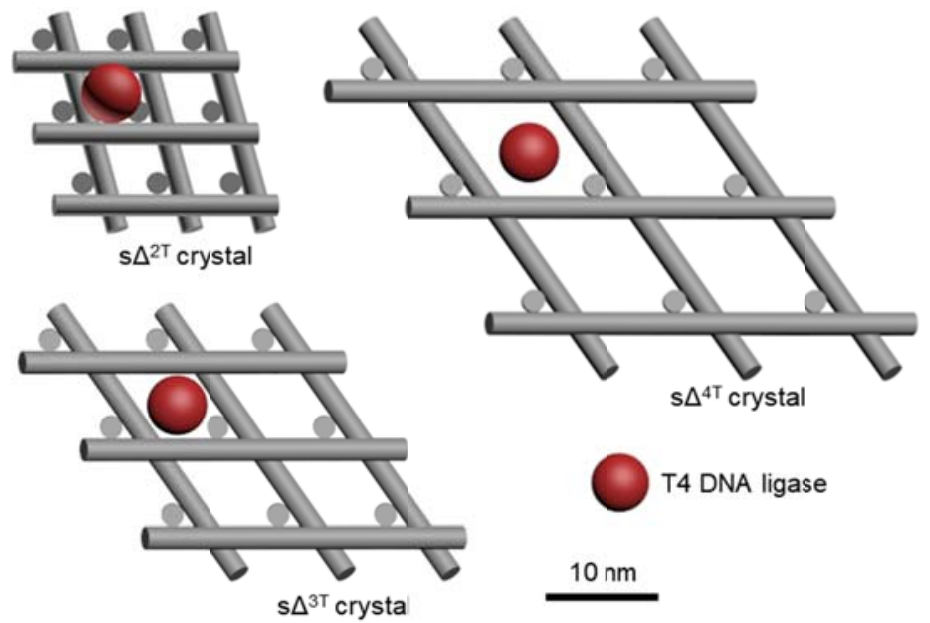

Fig. S3. Size comparison between DNA crystal pores and T4 DNA ligase. The crystal lattice and ligase are represented by rods and sphere, respectively. The rods represented DNA duplex. The size of T4 ligase is estimated from its molecular weight and is represented as a sphere for simplicity. The triangular units in the crystal need to be at least three helical turns of DNA in length for the ligase to penetrate the crystal pore. 

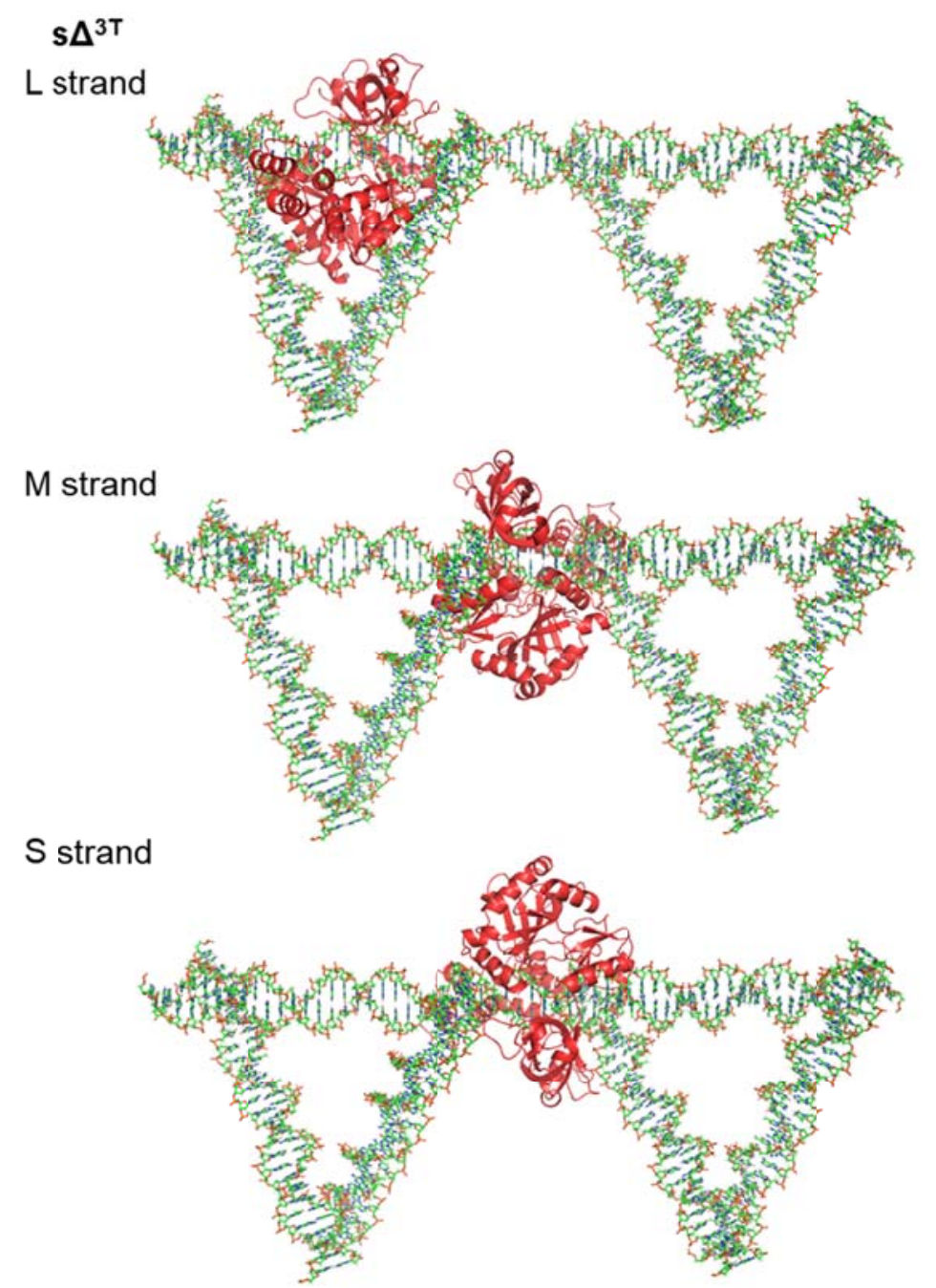

Fig. S4. Alignment of atomic T4 DNA ligase model with CanDo generated $\mathbf{s} \Delta^{3 \mathrm{~T}}$ dimers. T4 DNA ligase model was modified from PDB 6dt1. The DNA substrate was aligned with the ligation sites on L, M and S strand, and was then hided from presentation. Aligned models revealed strong steric hindrance at all ligation sites. 


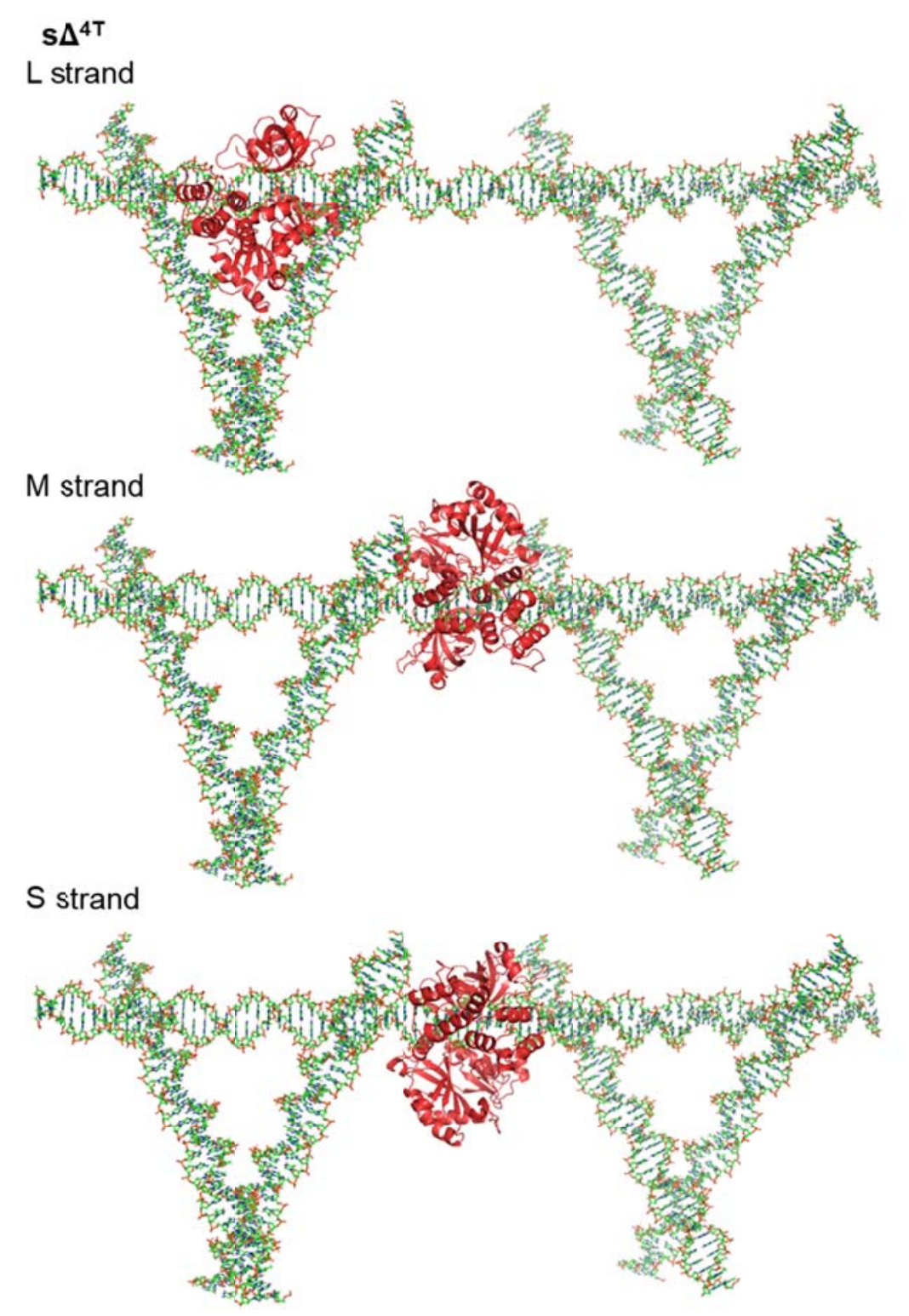

Fig. S5. Alignment of atomic T4 DNA ligase model with CanDo generated $\mathbf{s} \Delta^{4 T} \operatorname{dimers}$. T4 DNA ligase model was modified from PDB 6dt1. The DNA substrate was aligned with the ligation sites on L, M and S strand, and was then hided from presentation. Aligned models for M and $\mathrm{S}$ strands revealed sufficient space for ligase accessibilities. 


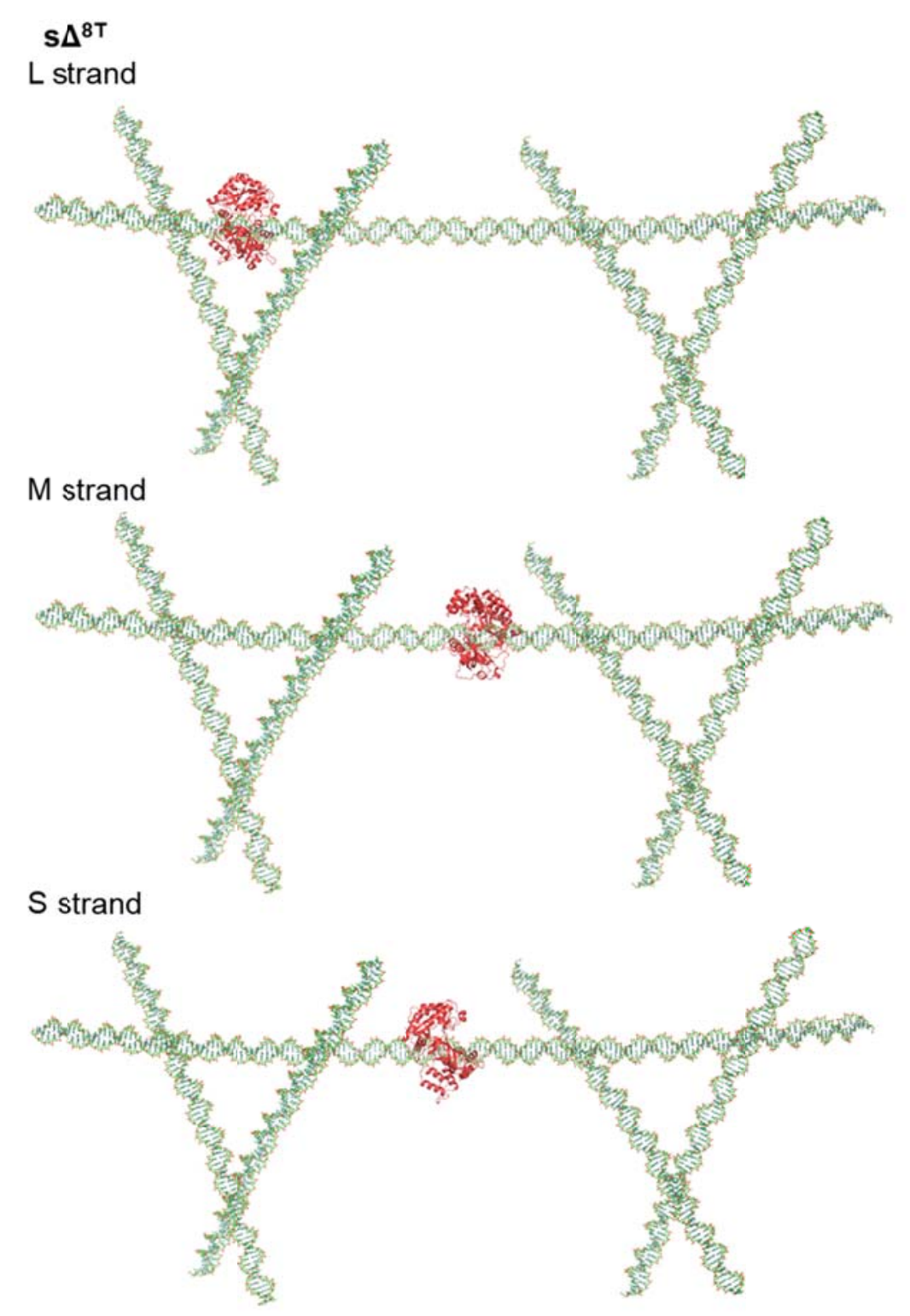

Fig. S6. Alignment of atomic T4 DNA ligase model with CanDo generated $\mathbf{s} \Delta^{8 \mathrm{~T}}$ dimers. T4 DNA ligase model was modified from PDB 6dt1. The DNA substrate was aligned with the ligation sites on $\mathrm{L}, \mathrm{M}$ and $\mathrm{S}$ strand, and was then hided from presentation. All aligned models demonstrated no steric hindrance. 


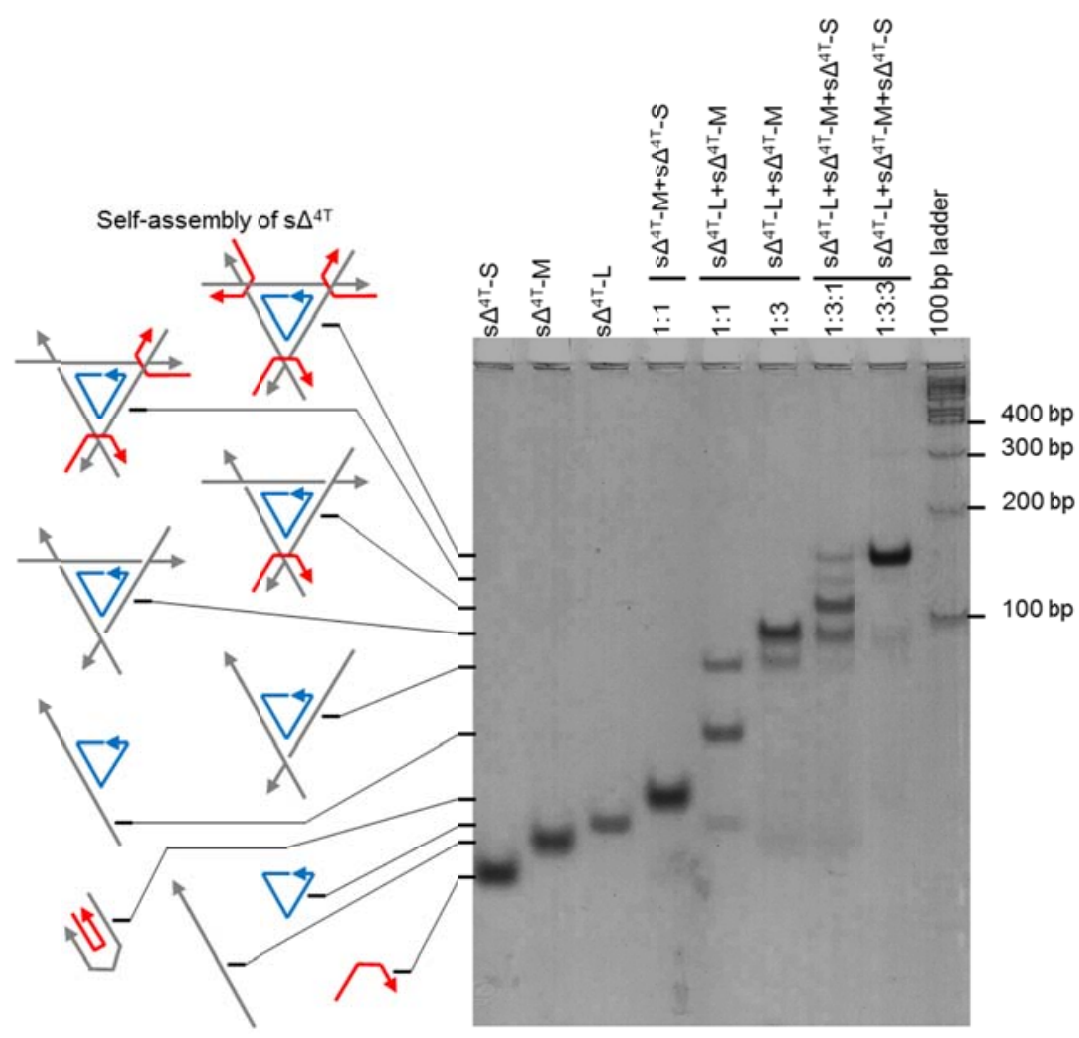

Fig. S7. Native PAGE (6\%) analysis of DNA $s \Delta^{4 T}$ motif. DNA sample compositions (strands and their molar ratios) and the identities of all the bands are indicated above and the sides of the gel image, respectively. The last lane on the right contains DNA duplex size markers. 


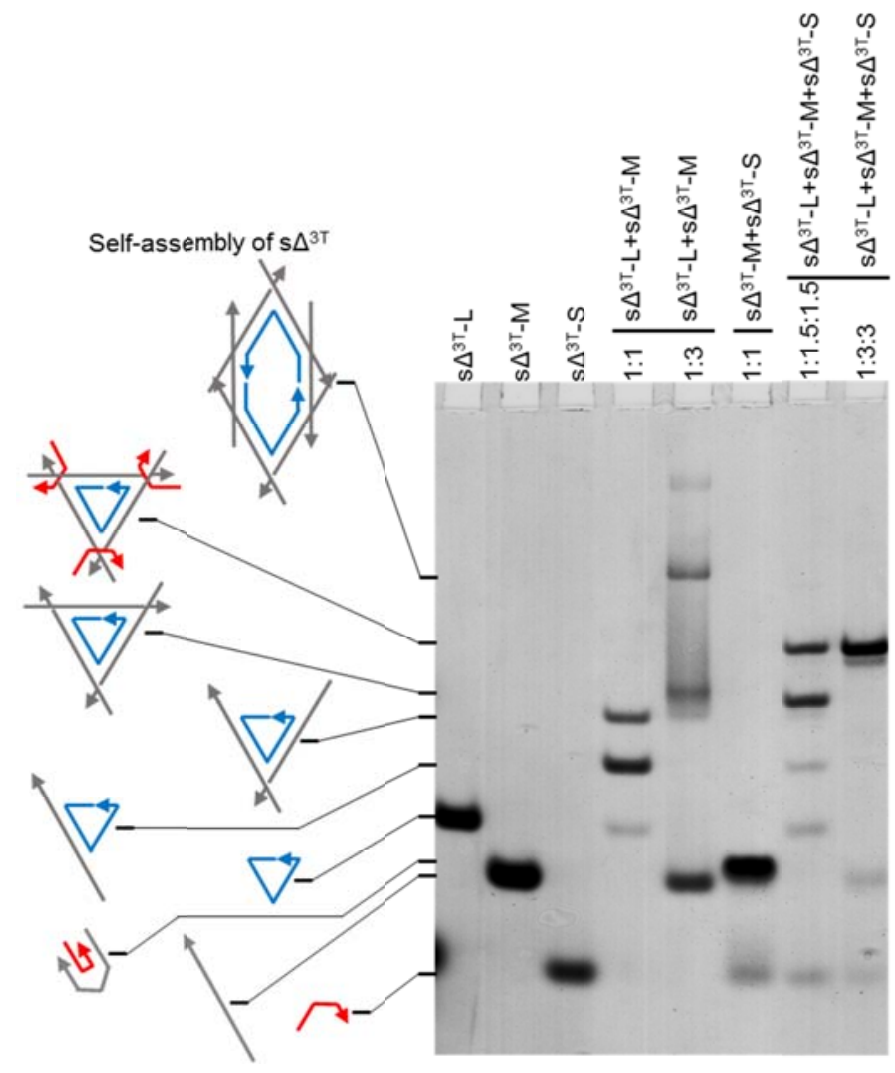

Fig. S8. Native PAGE (6\%) analysis of DNA $s \Delta^{3 T}$ motif. DNA sample compositions (strands and their molar ratios) and the identities of all the bands are indicated above and beside the gel image, respectively. 


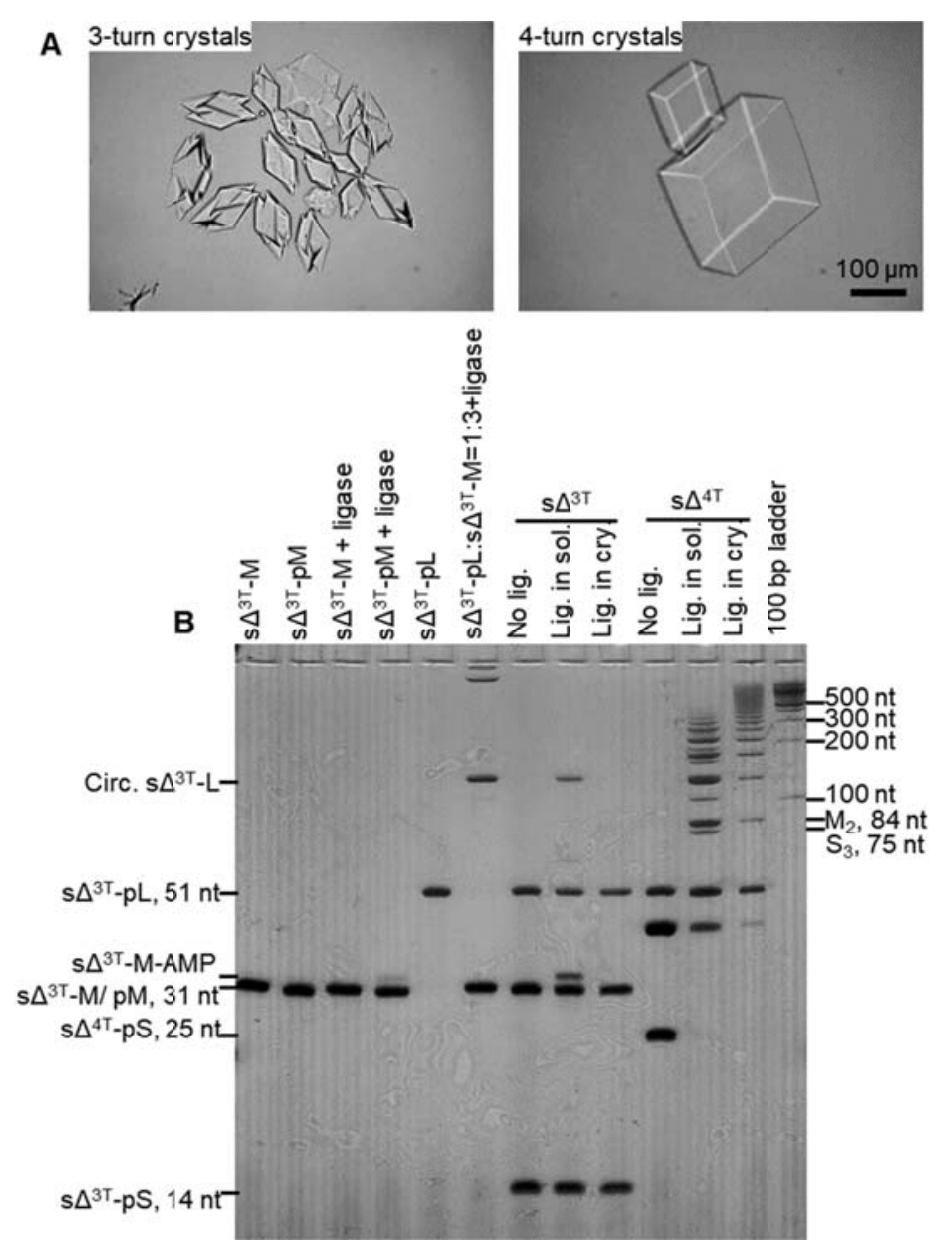

Fig. S9. Ligation of DNAs of $s \Delta^{3 T}$ and $s \Delta^{4 T}$ in solution and in crystal. (A) Optical images of DNA $s \Delta^{3 \mathrm{~T}}$ crystals and DNA $\mathrm{s} \Delta^{4 \mathrm{~T}}$ triangle crystals during ligation. (B) $20 \%$ denaturing PAGE for the ligation of DNA $s \Delta^{3 \mathrm{~T}}$ and $\mathrm{s} \Delta^{4 \mathrm{~T}}$ in solution and in crystal. The prefix "p" represents 5' phosphorylation. $\mathrm{s} \Delta^{3 \mathrm{~T}}$ have minimal ligation yield in solution and in crystal, while $\mathrm{s} \Delta^{4 \mathrm{~T}}$ have high ligation yield in solution and in crystal. The ligation of $\mathrm{s} \Delta^{4 \mathrm{~T}}$ in crystal resulted in higher molecular weight distribution than in solution, indicating a higher degree of linkage. 

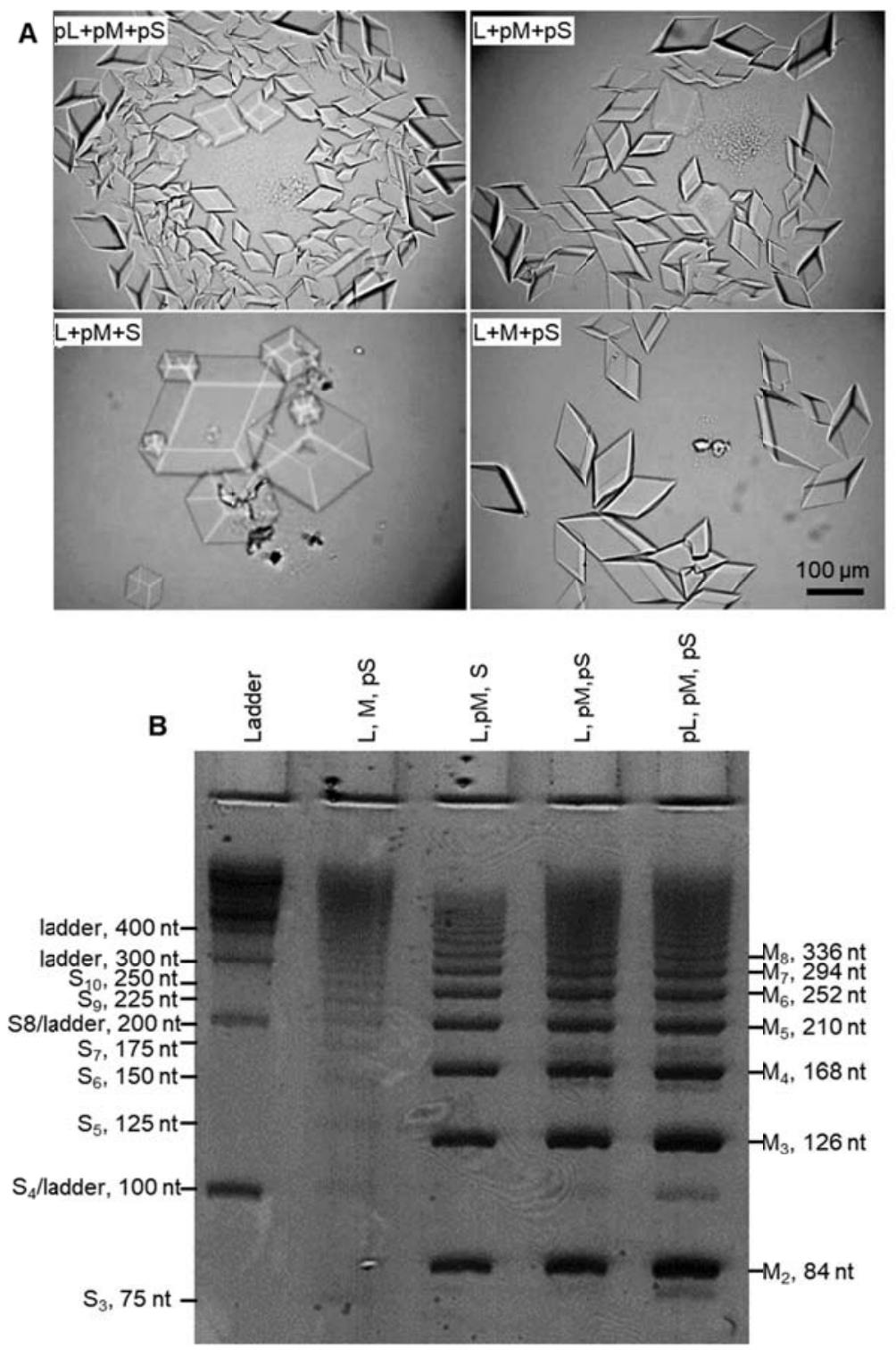

Fig. S10. Crystallization and ligation of DNA $s \Delta^{4 T}$ crystals with different phosphorylation sites. (A) Optical images of DNA crystals with different combinations of phosphorylated strands. The prefix " $p$ " represents 5' phosphorylation. (B) Zoom-in image of denaturing PAGE in Fig. 1C. Oligomers from strand $\mathrm{S}$ and strand $\mathrm{M}$ are assigned in the gel. 

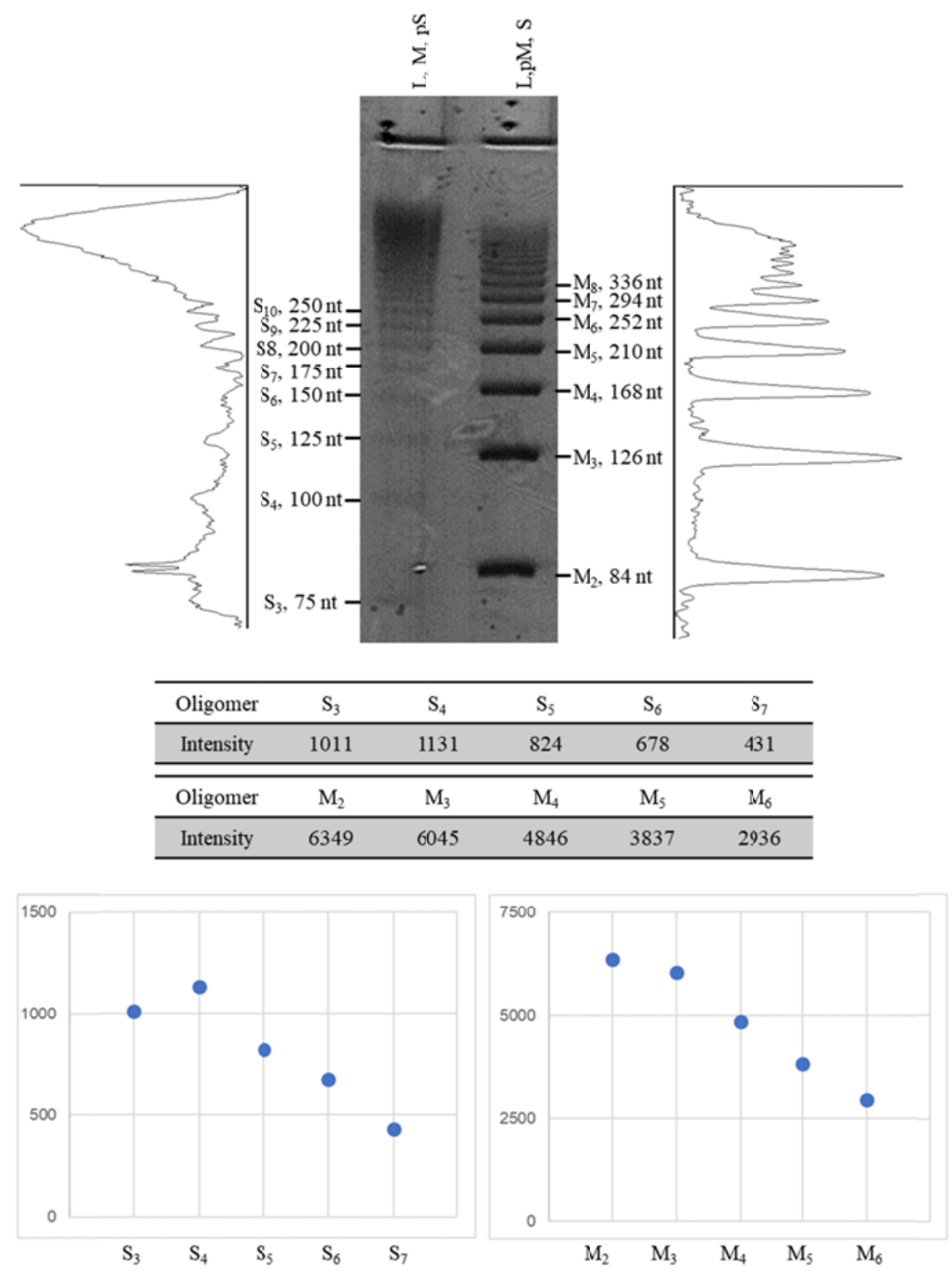

Fig. S11. Size distribution of ligated $M$ and $S$ oligomers in ligated DNA $s \Delta^{4 T}$ crystals. The intensity along the lanes for ligated $\mathrm{S}$ and $\mathrm{M}$ strands were plotted and measured by ImageJ, respectively. Because of relatively low intensity, the plot for S oligomers is too blur to accurately measure individual bands. Assuming proportional intensity-mass relationship, a trend of decreasing portion of high molecular weight concatemers can be observed for both $\mathrm{S}$ and $\mathrm{M}$ strands. 


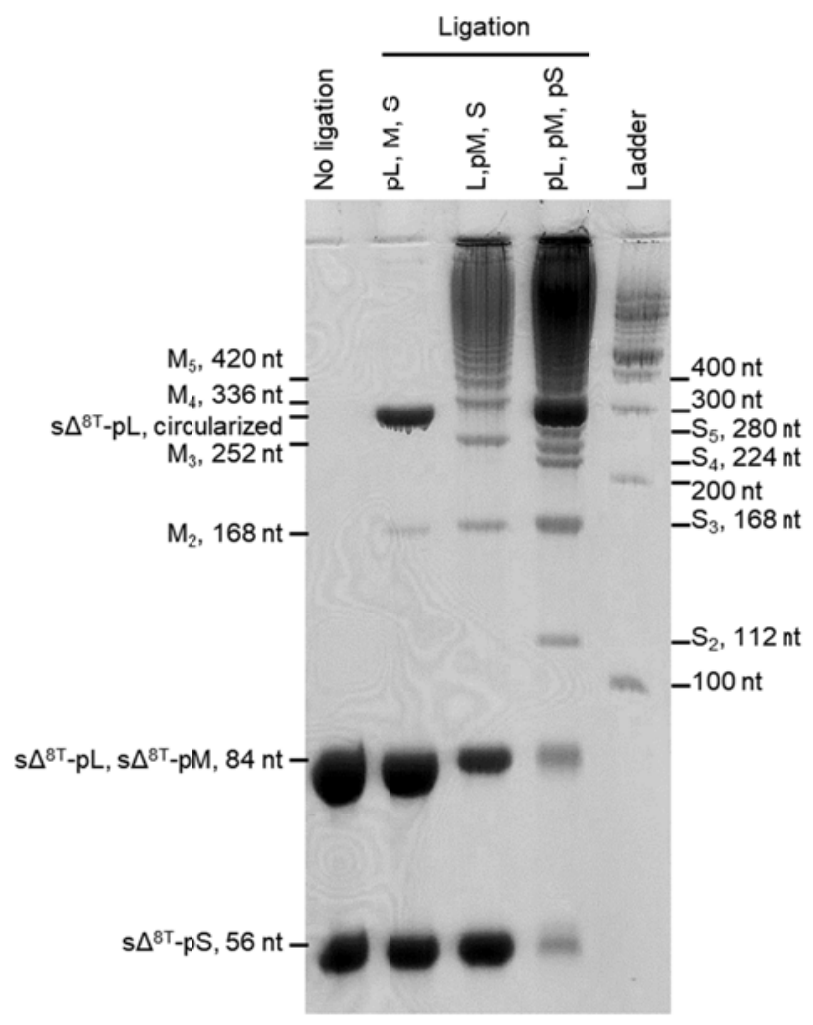

Fig. S12. 15\% denaturing PAGE analysis of DNA $s \Delta^{8 \mathrm{~T}}$ ligation. 


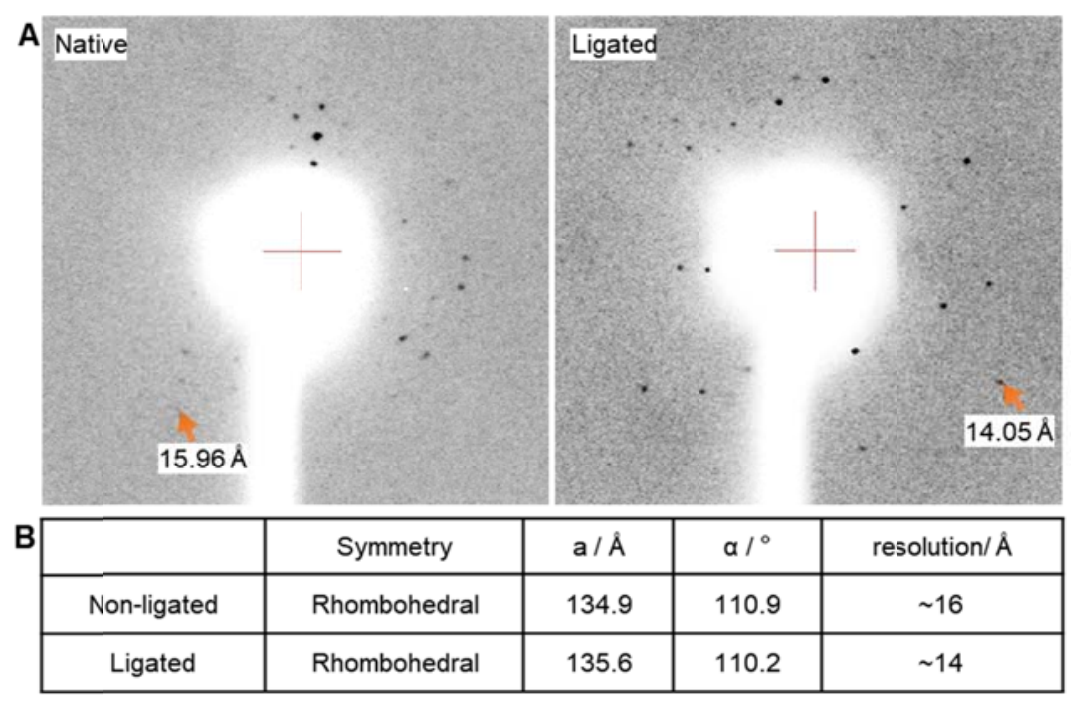

Fig. S13. X-ray diffraction of DNA $s \Delta^{4 T}$ crystals. (A) Diffraction patterns of native and ligated DNA s $\Delta 4 \mathrm{~T}$ crystals. Data were collected on a home source Rigaku RU-H2R. For each crystal, 5 images of diffraction data were collected from $0 \sim 180^{\circ}$ at $45^{\circ}$ interval, with $2^{\circ}$ oscillation angle, and the best resolution image was chosen for presentation. (B) Comparison between unit cell parameters of native and ligated DNA $s \Delta^{4 \mathrm{~T}}$ crystals. The native crystal parameters are from a previous publication ${ }^{5}$. Native crystal and ligated crystal share the same crystallographic symmetry and have similar unit cell parameters. 

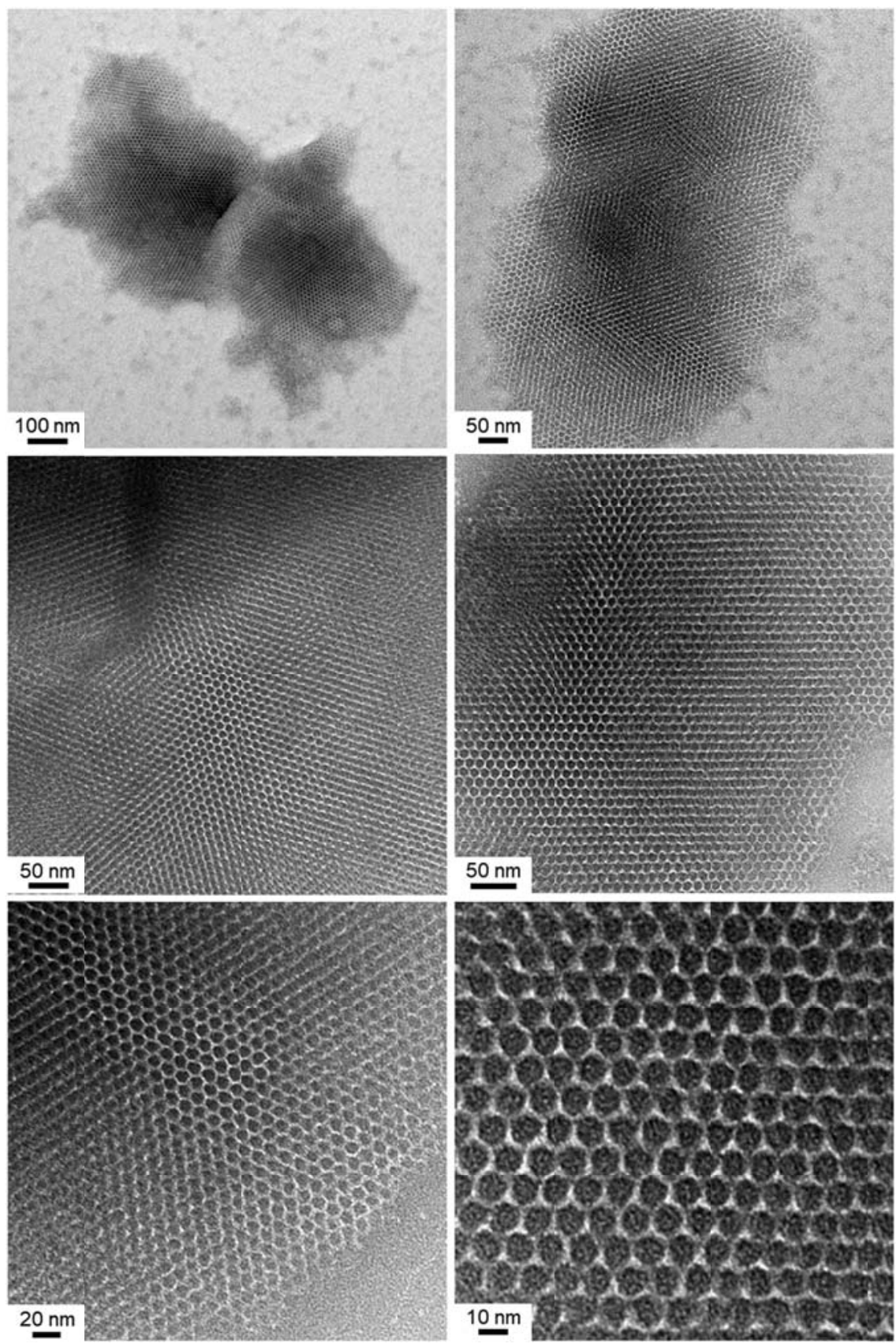

Fig. S14. Negative-stained TEM images of native, crushed DNA $s \Delta^{4 T}$ crystals. Images of different magnifications are shown. Crystal pieces with various number of layers were observed. In some areas (e.g., the last image), the motifs may have collapsed during sample preparation. 

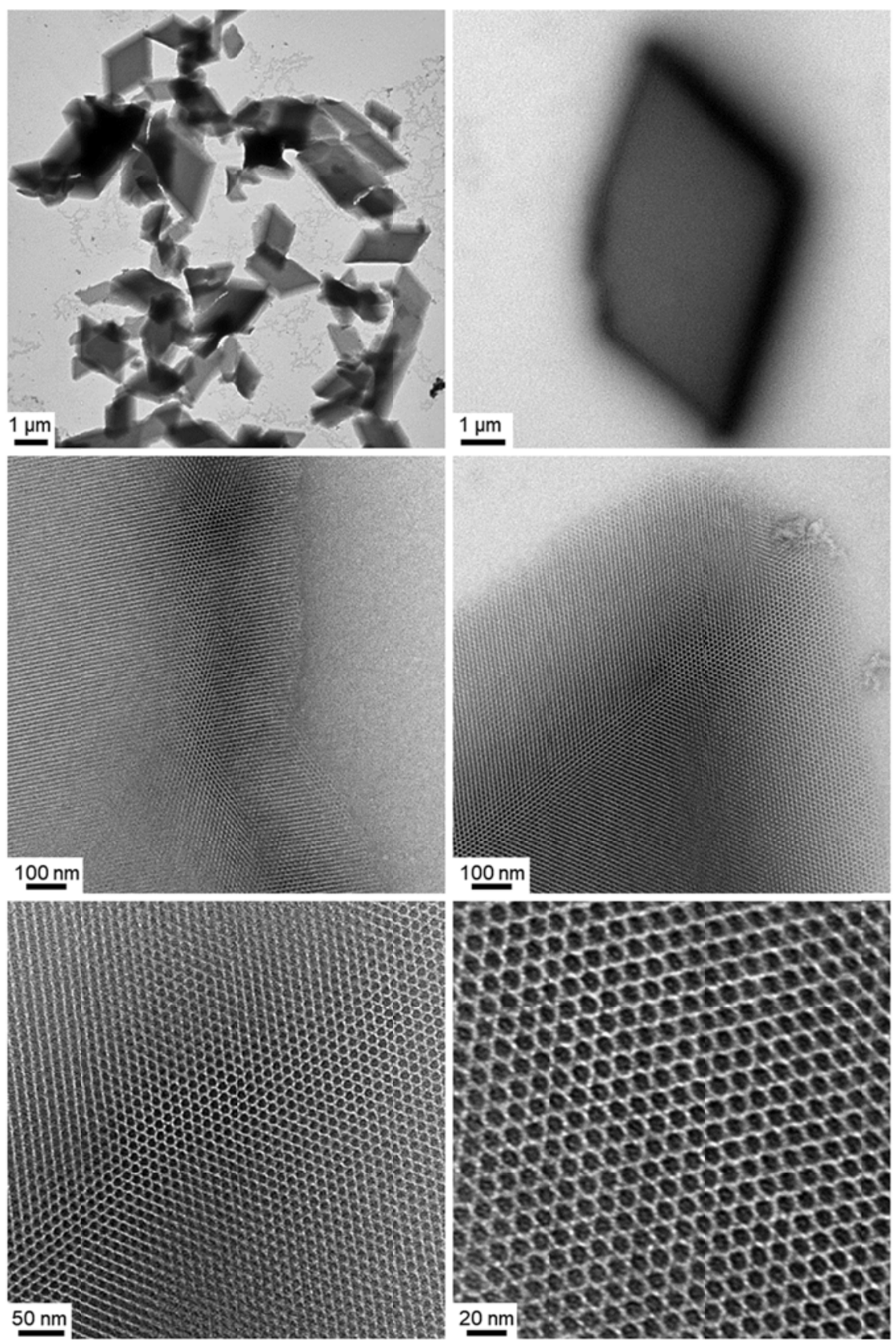

Fig. S15. Negative-stained TEM images of native DNA a $\Delta^{4 T}$ microcrystals. Images of different magnifications are shown. Single crystals of rhombohedral shapes were observed. Less distortion of crystal lattices was found in these samples compared with Fig. S10. 

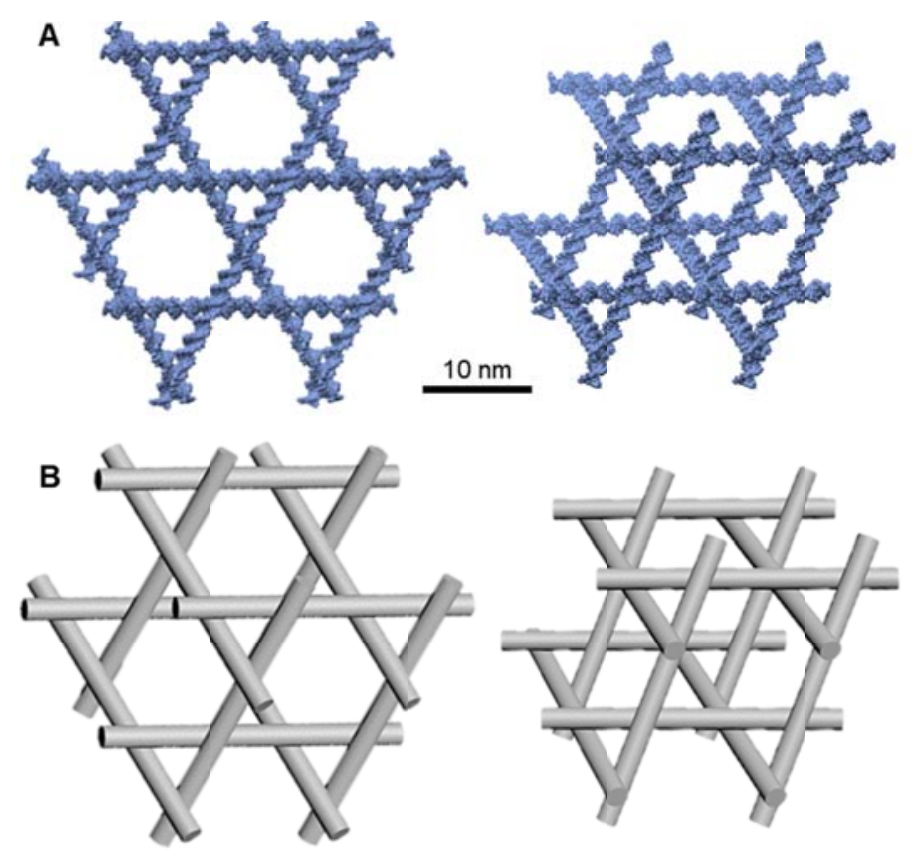

Fig. S16. CanDo model and rod model of DNA $s \Delta^{4 T}$ crystal. (A) CanDo atomic model of the unit cell of 4-turn DNA tensegrity triangle crystal. (B) Rod model built in 3ds MAX according to the DNA design and unit cell parameters from X-ray diffraction. 

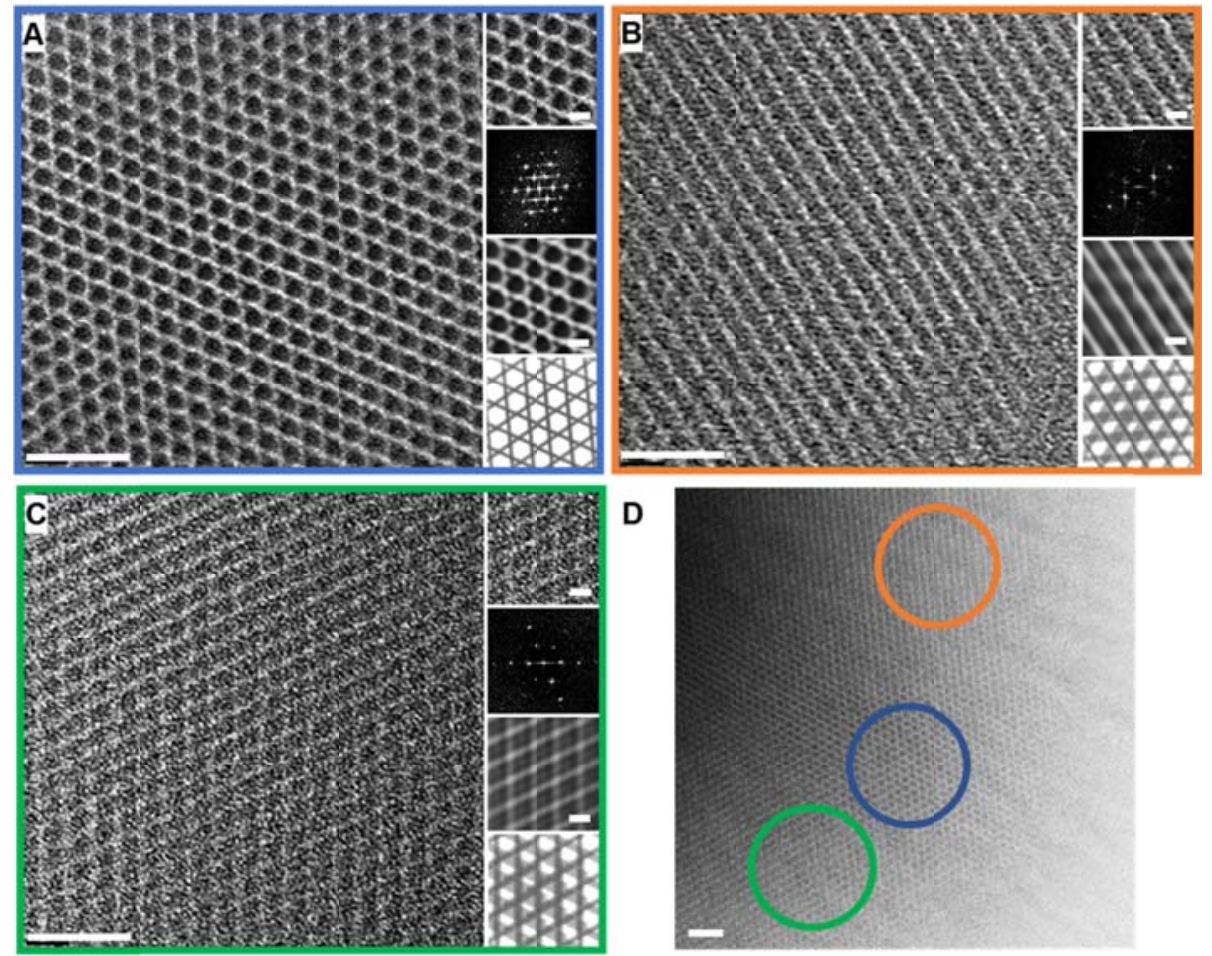

Fig. S17. Different types of lattice patterns observed in TEM images of native DNA $a \Delta^{4 T}$ crystals. (A-C) Three different lattice patterns observed in microcrystals of asymmetric 4-turn DNA triangle $\left(\mathrm{a} \Delta^{4 \mathrm{~T}}\right)$ without ligation. Right panels of each image, top to bottom: Zoomed-in image of patterns; Fourier transform (FFT); Reconstructed, zoom-in image from FFT; $5 \times 5 \times 5$ rod model of the crystal lattice. (D) A single crystalline area with all three patterns. Scale bars in all large-area images: $50 \mathrm{~nm}$. Scale bars in panels: $10 \mathrm{~nm}$. 


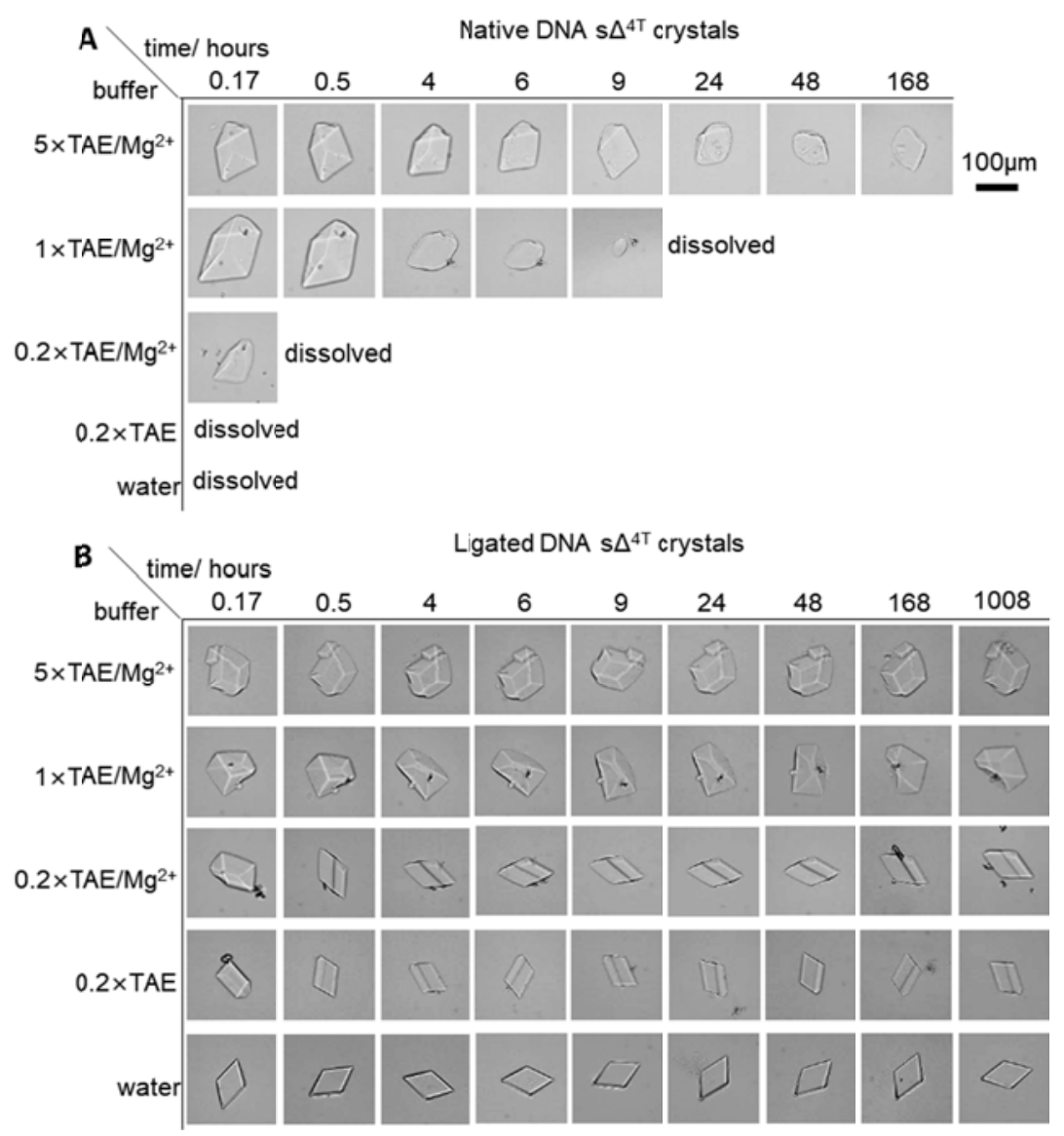

Fig. S18. Stability of ligated DNA $s \Delta^{4 T}$ crystals under different ionic strengths. Optical images were taken for native and ligated DNA $s \Delta^{4 T}$ crystals incubated in buffers of decreasing ionic strength. Ligated crystals remained intact without any change in morphology in all tested buffers. 


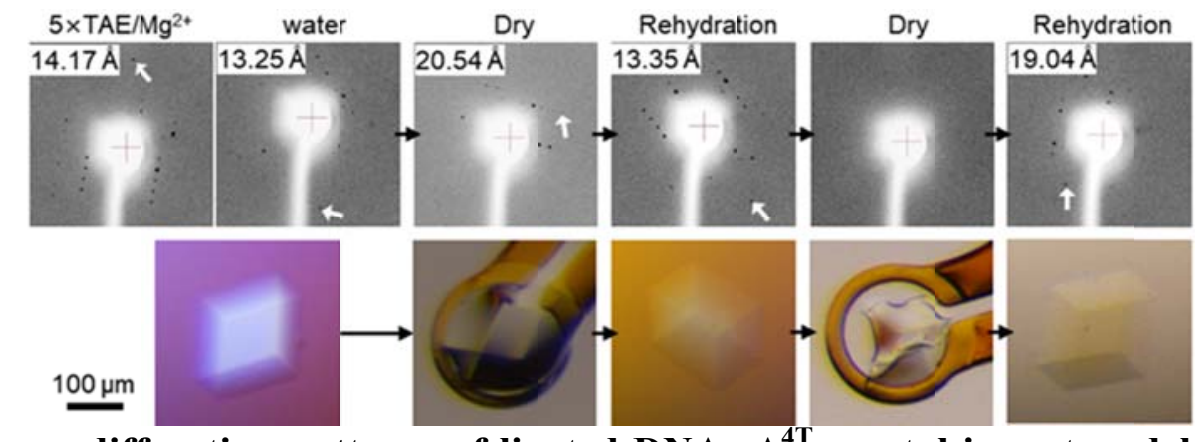

Fig. S19. X-ray diffraction patterns of ligated DNA $s \Delta^{4 \mathrm{~T}}$ crystal in water, dehydrated and rehydrated. All samples contain $30 \%$ glycerol as cryoprotectant except in the second "Dry" image, where glycerol was removed to ensure complete drying. The best diffraction resolution of each sample is listed at the top, left corner of each diffraction image. The crystal had a similar diffraction resolution in the crystallization buffer $5 \times \mathrm{TAE} / \mathrm{Mg}^{2+}$ and water. Diffractions became worse when partially dried with glycerol and lost in detection range when completely dried. After rehydration with water ( $30 \%$ glycerol), the diffractions recovered, indicating the recovery of crystallinity. Besides dry and rehydration, crystal also went through freeze-thaw cycles. During diffraction, the crystal was frozen at $100 \mathrm{~K}$, and for optical microscope imaging, the crystal was thawed to room temperature. 


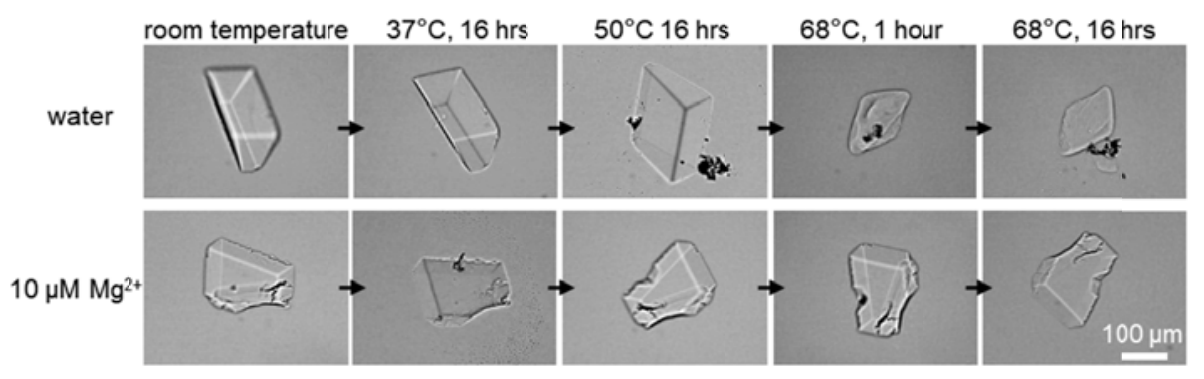

Fig. S20. Thermostability of ligated DNA $s \Delta^{4 \mathrm{~T}}$ crystals at low ionic strength. Ligated DNA $\mathrm{s} \Delta{ }^{4 \mathrm{~T}}$ crystals were washed extensively (see materials and methods) by water or $10 \mu \mathrm{M}$ of $\mathrm{Mg}(\mathrm{OAc})_{2}$ solution before incubation. Both crystals were transferred and rewashed every time for elevated temperature. 


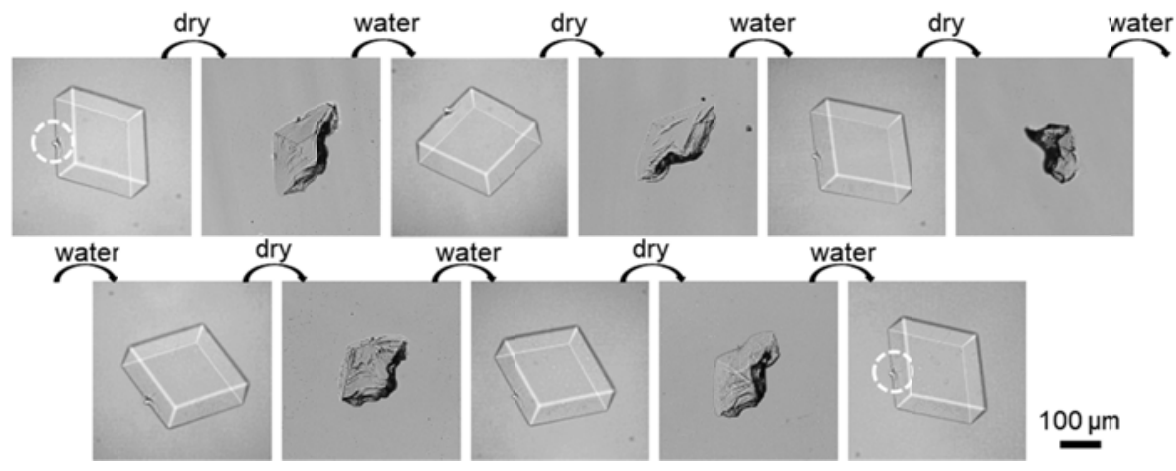

Fig. S21. Dry and rehydration cycles of ligated DNA $\mathbf{s} \Delta^{4 \mathrm{~T}}$ crystal in water. DNA $\mathrm{s} \Delta^{4 \mathrm{~T}}$ crystal was extensively washed in water before the cycles. A small crack was created on crystal during handling (circled in the first and the last image), and no change was observed even for the crack during cycles. 


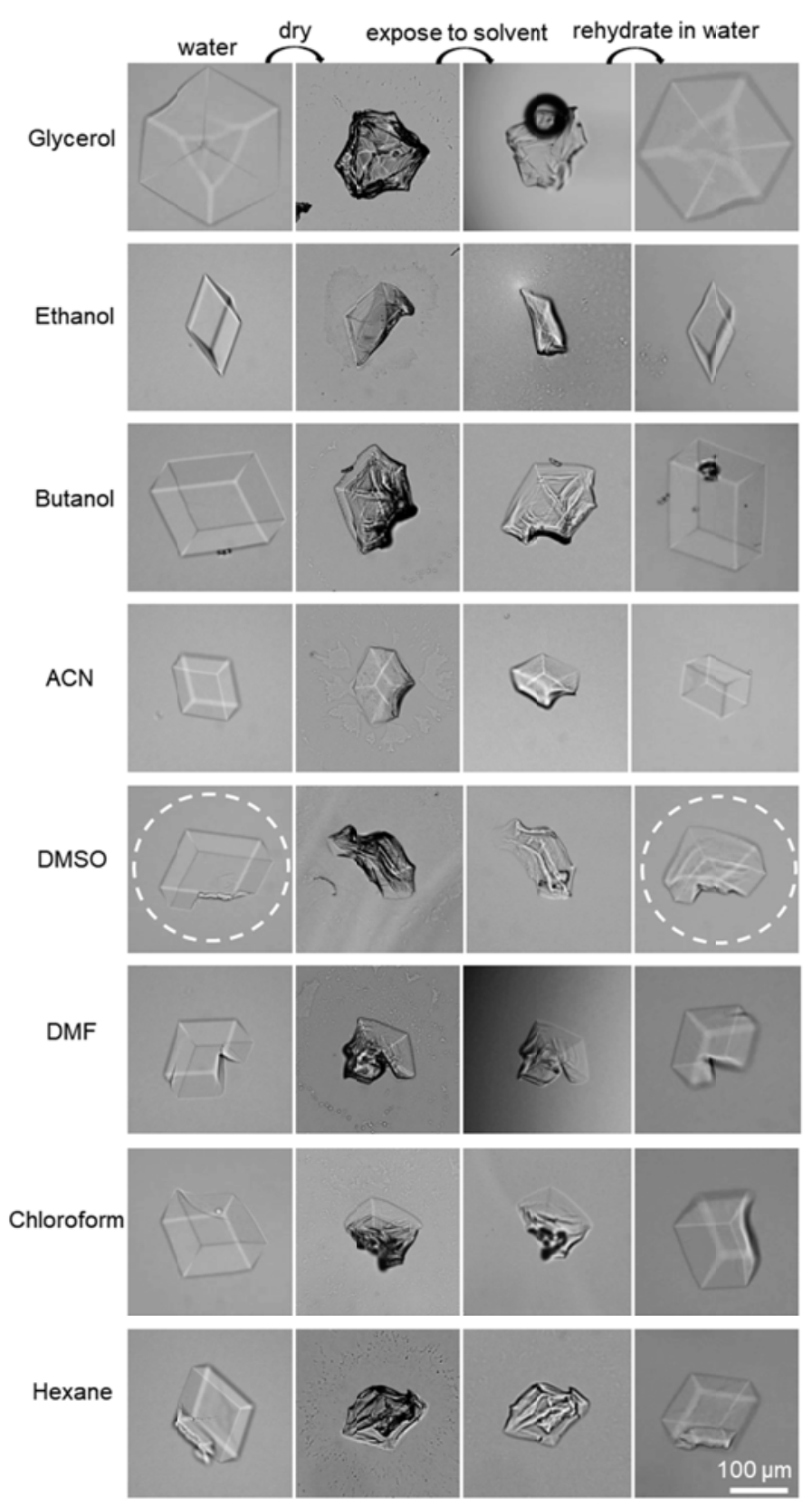

Fig. S22. Ligated DNA $s \Delta^{4 T}$ crystals dehydrated and exposed to organic solvents. Dried DNA crystals were soaked in organic solvents. In most solvents, crystal went back into original size and morphology when rehydrated with water. In DMSO, crystal collapsed, possibly because of the denaturing property of DMSO. 


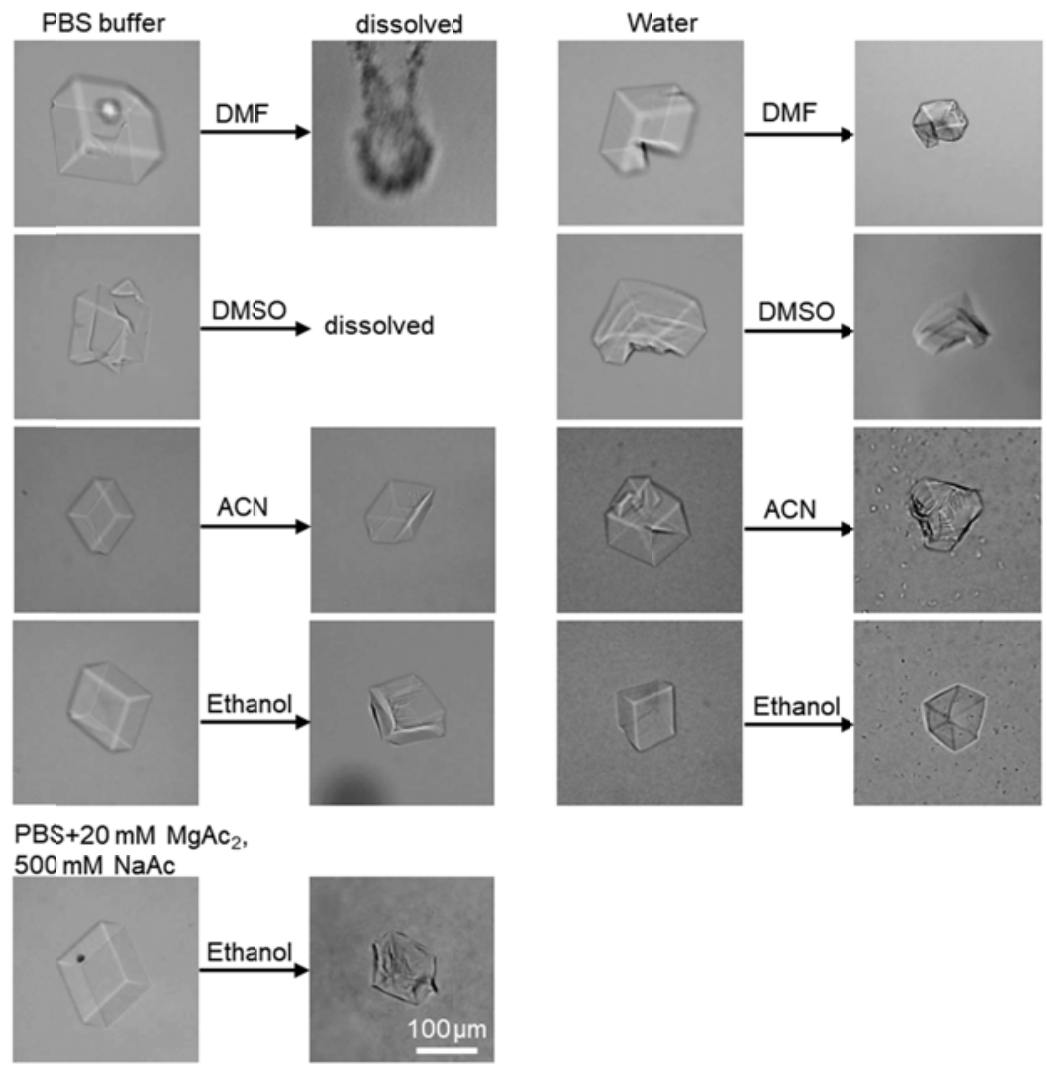

Fig. S23. Ligated DNA $s \Delta^{4 \mathrm{~T}}$ crystals exposed to aqueous solution mixed with organic solvents at 1:1 volume ratio. Though DMF and DMSO alone could not dissolve dry, ligated crystal, when they were mixed with PBS buffer, crystals fully dissolved. Other solvent mixtures created different extent of morphology change in the crystals, possibly because of the change in interactions between neighboring DNA duplex in the crystal. 

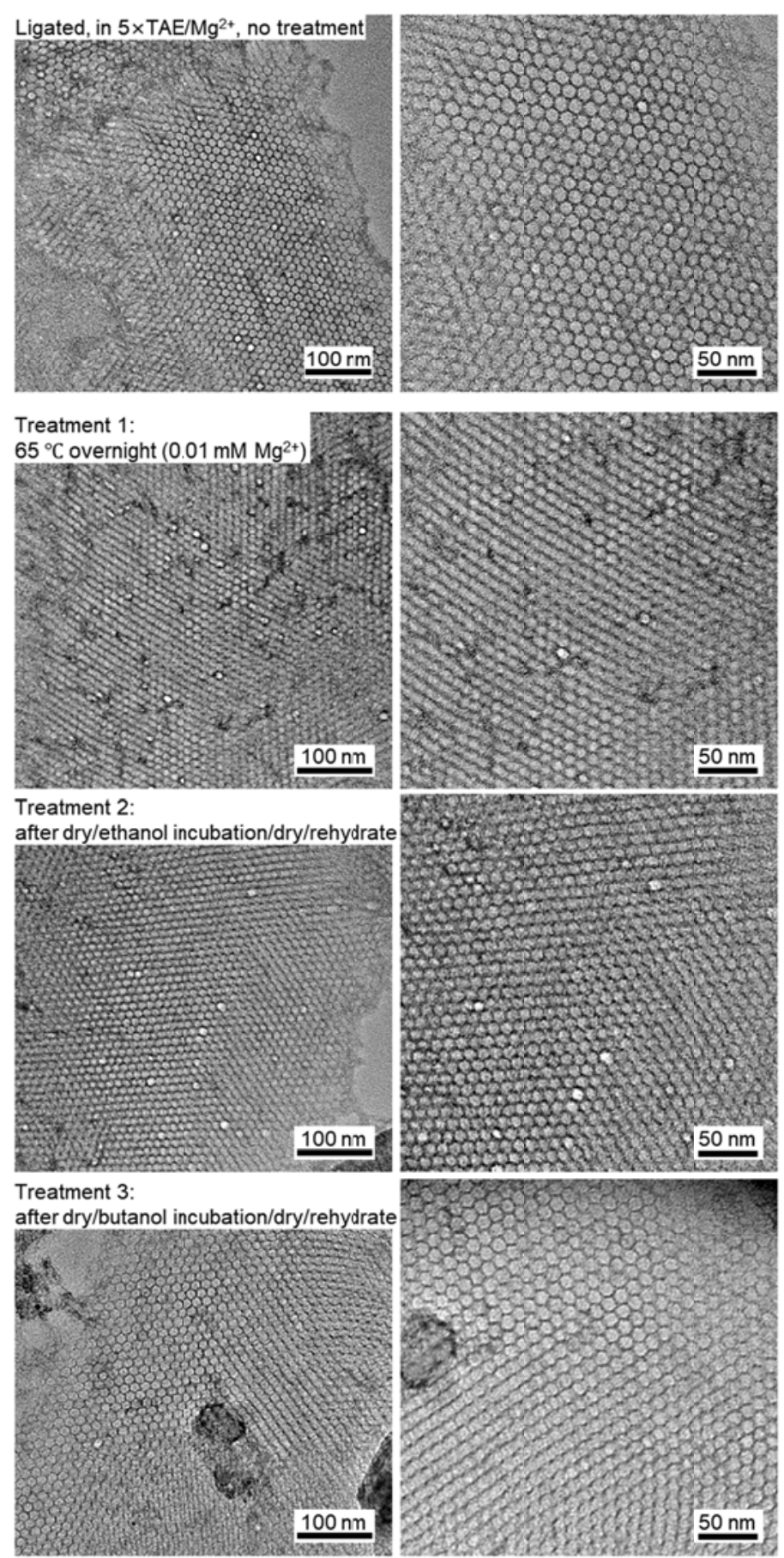

Fig. S24. Negatively stained TEM images of ligated DNA $s \Delta^{4 T}$ crystals before and after stability tests. The ligated microcrystals were imaged before and after treatments. From the same batch, crystals were tested by three different treatments in parallel: 1 . Incubation at $65{ }^{\circ} \mathrm{C}$ overnight in $10 \mu \mathrm{M} \mathrm{Mg}^{2+}$; 2 . Washed by water, dried on glass slide, incubated with ethanol, dried again and rehydrated by water; 3 . Similar process as 2 , while using butanol instead of ethanol. By comparison we can see the nanoscale crystal lattices were preserved well upon all three different treatments, which confirmed the stability of ligated DNA $s \Delta^{4 \mathrm{~T}}$ crystals. 

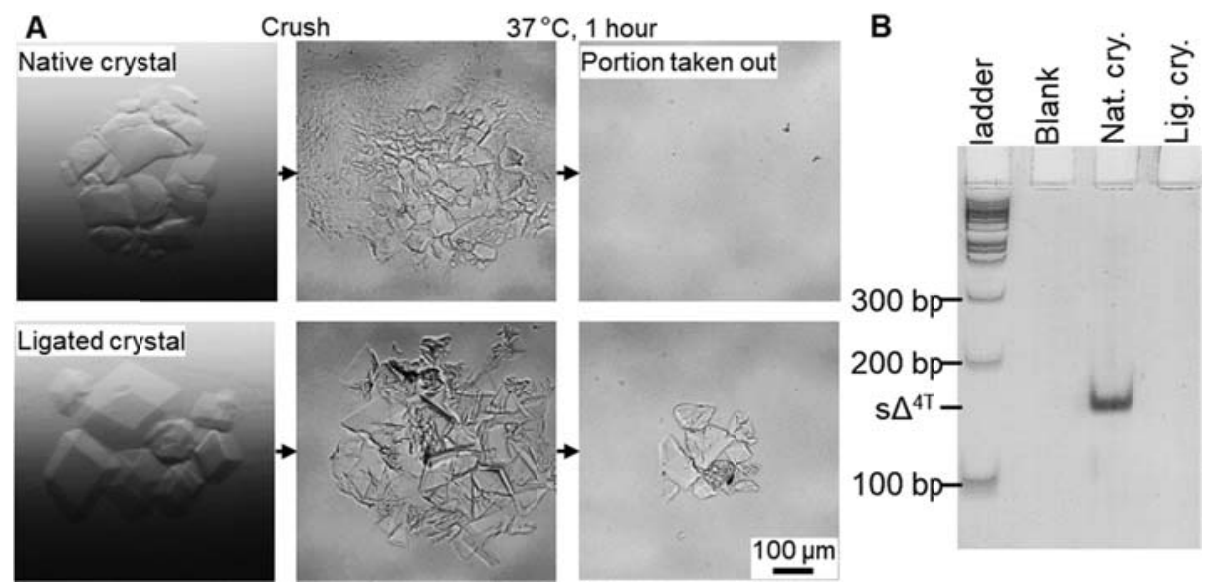

Fig. S25. Native PAGE analysis of ligated DNA $\mathbf{s} \Delta^{4 T}$ crystals. (A) Native and ligated DNA crystals were crushed by similar methods using cryoloop in $1 \times \mathrm{TAE} / \mathrm{Mg}^{2+}$ buffer. After further incubation at $37{ }^{\circ} \mathrm{C}$, portions were taken out to check the dissolution. (B) $6 \%$ native PAGE analysis of the crushed and dissolved products of crystals. No band can be found for ligated crystals since they did not solve. 

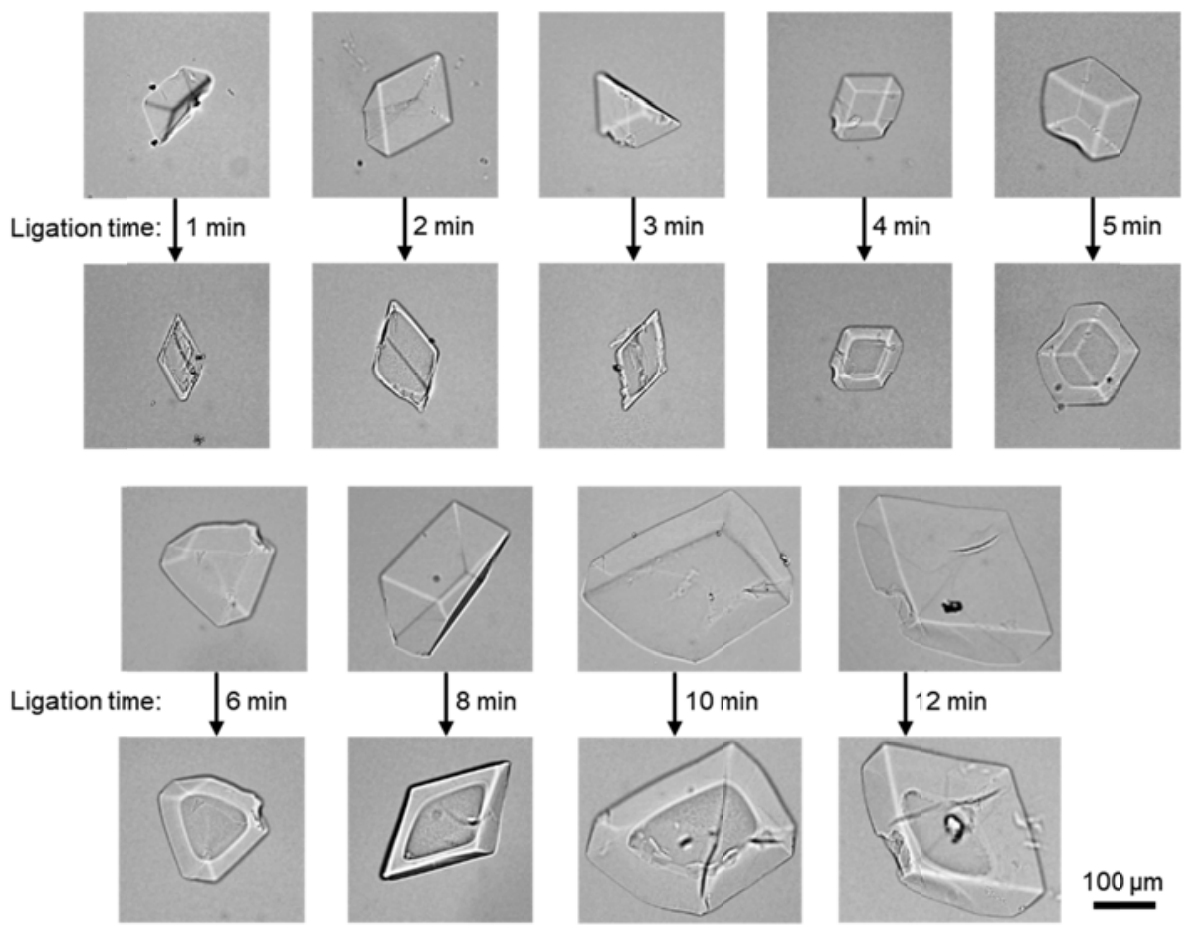

$100 \mu \mathrm{m}$

Fig. S26. DNA crystal shells prepared with different ligation time. The crystals were ligated in 80 units $/ \mu \mathrm{L}$ T4 DNA ligase, $1 \mathrm{mM} \mathrm{ATP}, 5 \times \mathrm{TAE} / \mathrm{Mg}^{2+}$. After ligation for certain time, the reaction was stopped by transferring the crystal into $1 \times \mathrm{TAE}$ with $0.5 \mathrm{M} \mathrm{NaCl}$. Further transferring into $0.5 \times \mathrm{TAE} / \mathrm{Mg}^{2+}$ initiated the dissolution of the crystal interiors and resulted in crystal shells. 


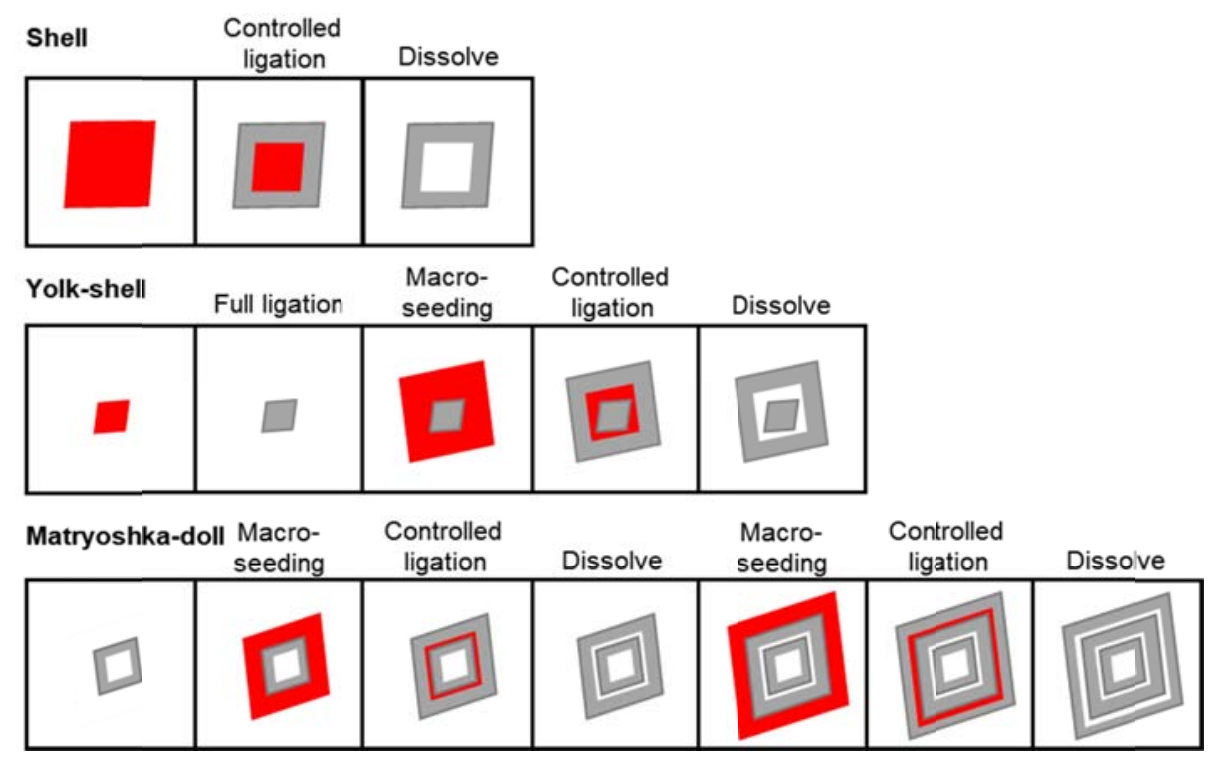

Fig. S27. Scheme for the preparation of DNA crystals with complex architectures. Controlled ligation and macro-seeding were combined for the preparation. Detailed protocols can be found in materials and methods. 


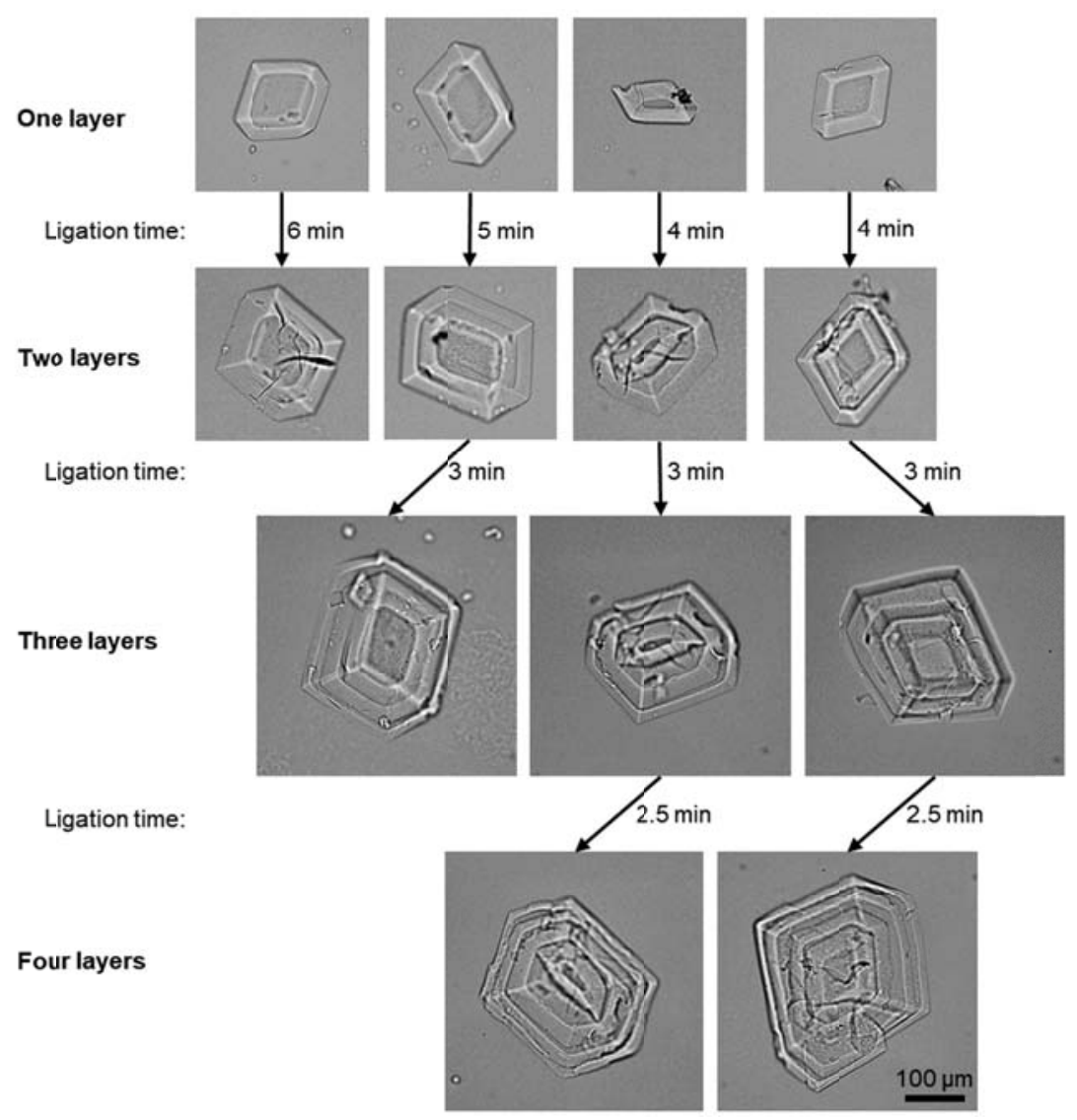

Fig. S28. The preparation of the multiple layers in matryoshka-doll DNA crystals. Layers were added stepwise by macroseeding and controlled ligation. The ligation time was tuned to obtain thin layers for better observation of the architectures. Long ligation time would ligate two adjunct layers into one, as in the first crystal. 

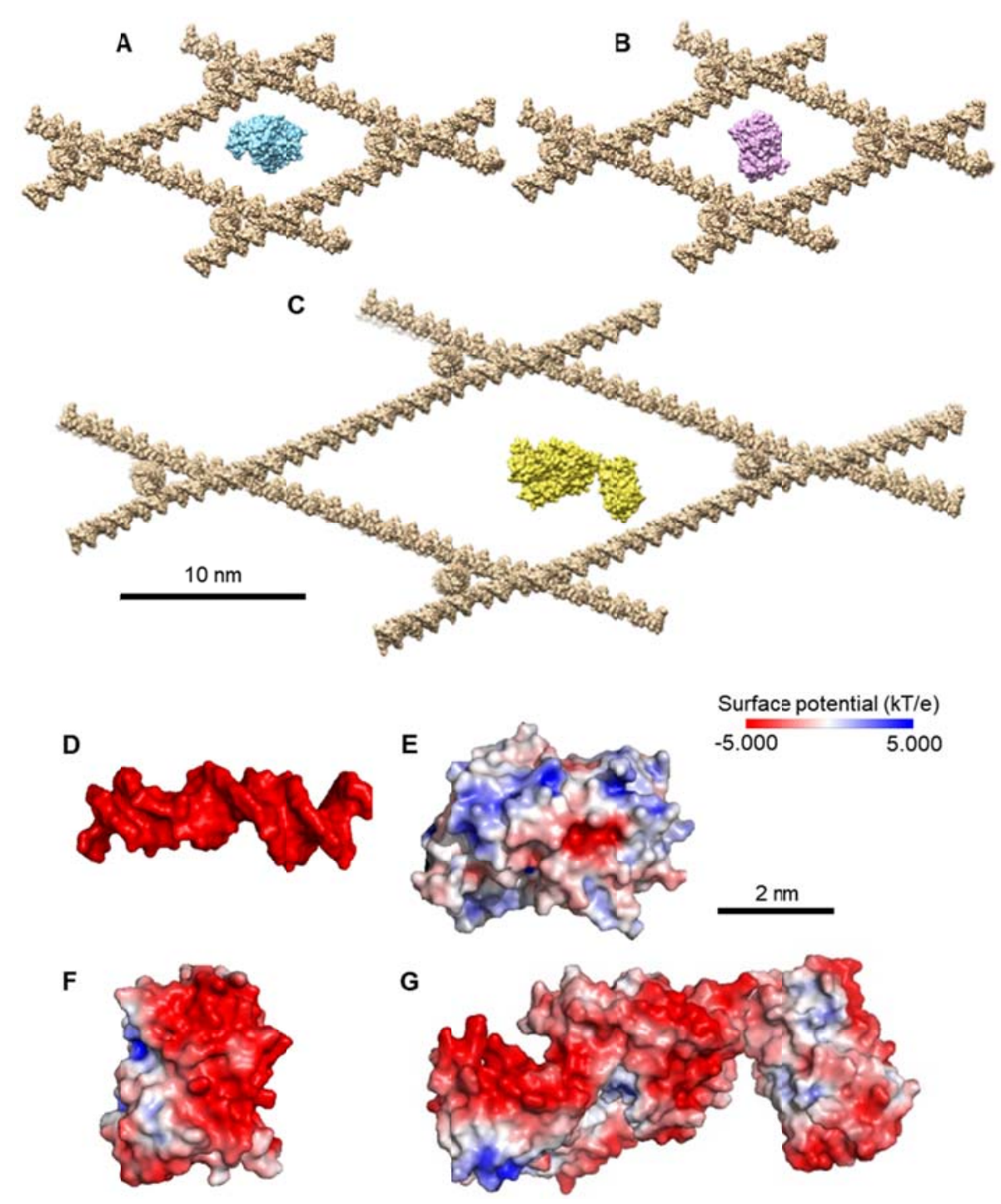

Fig. S29. Models for protein entrapment in DNA crystal. Atomic models for crystals were predicted by CanDo, and surface potentials were predicted by APBS (Adaptive PoissonBoltzmann Solver) electrostatics calculations. Blue: positively charged; Red: negatively charged. (A) to $(\mathbf{C})$ are on the same scale, and $(\mathbf{B})$ to $(\mathbf{G})$ are on the same scale. (A) $\Delta^{4 \mathrm{~T}}$ crystal unit cell with HRP. (B) $\Delta^{4 \mathrm{~T}}$ crystal unit cell with GFP. (C) $\Delta^{8 \mathrm{~T}}$ crystal unit cell with GFP-deaminase. (D) Surface potential of DNA duplex at pH 7.4. (E) Surface potential of HRP at pH 6. (F) Surface potential of GFP at $\mathrm{pH}$ 7.4. (G) Surface potential of HRP-deaminase at $\mathrm{pH}$ 7.4. 


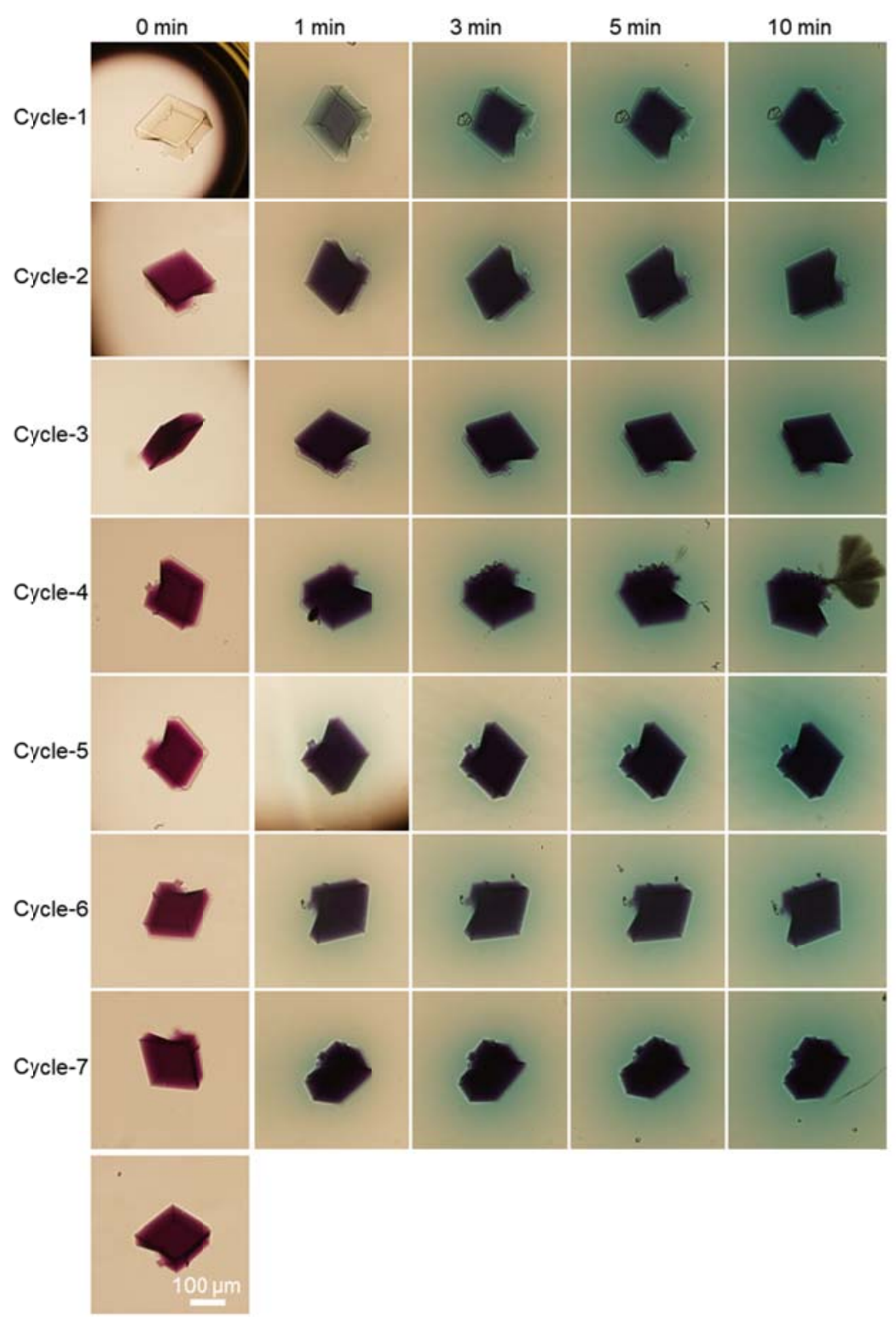

Fig. S30. Ligated DNA $s \Delta^{4 \mathrm{~T}}$ crystals immobilized with HRP for catalysis in $0.1 \mathrm{M} \mathrm{KH}_{2} \mathrm{PO}_{4}$, pH 5, as a reusable heterogeneous catalyst. For seven cycles of catalysis, optical images were taken every 5 mins. Green oxidation products of ABTS were observed diffusing out from the crystal. 
A

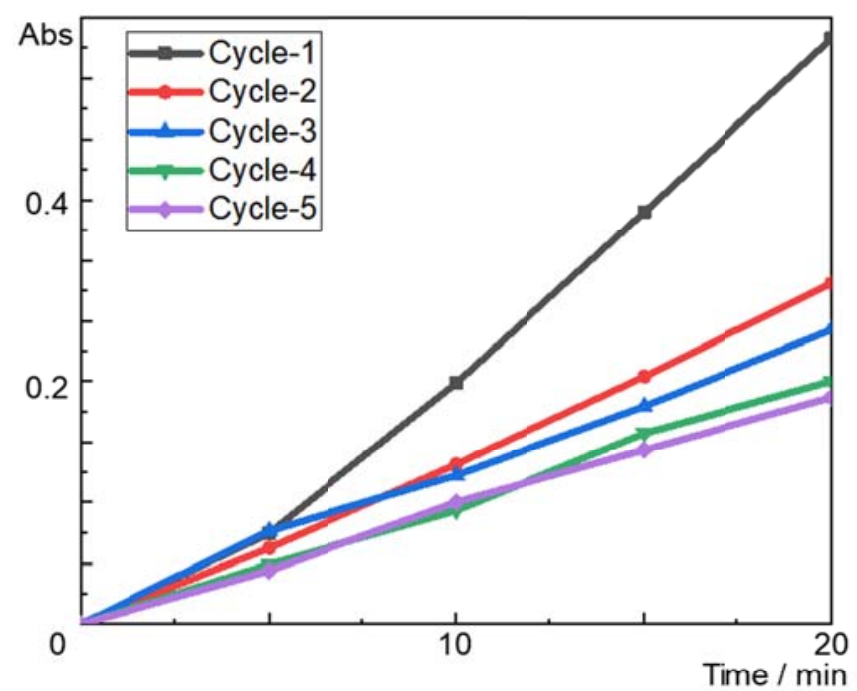

B
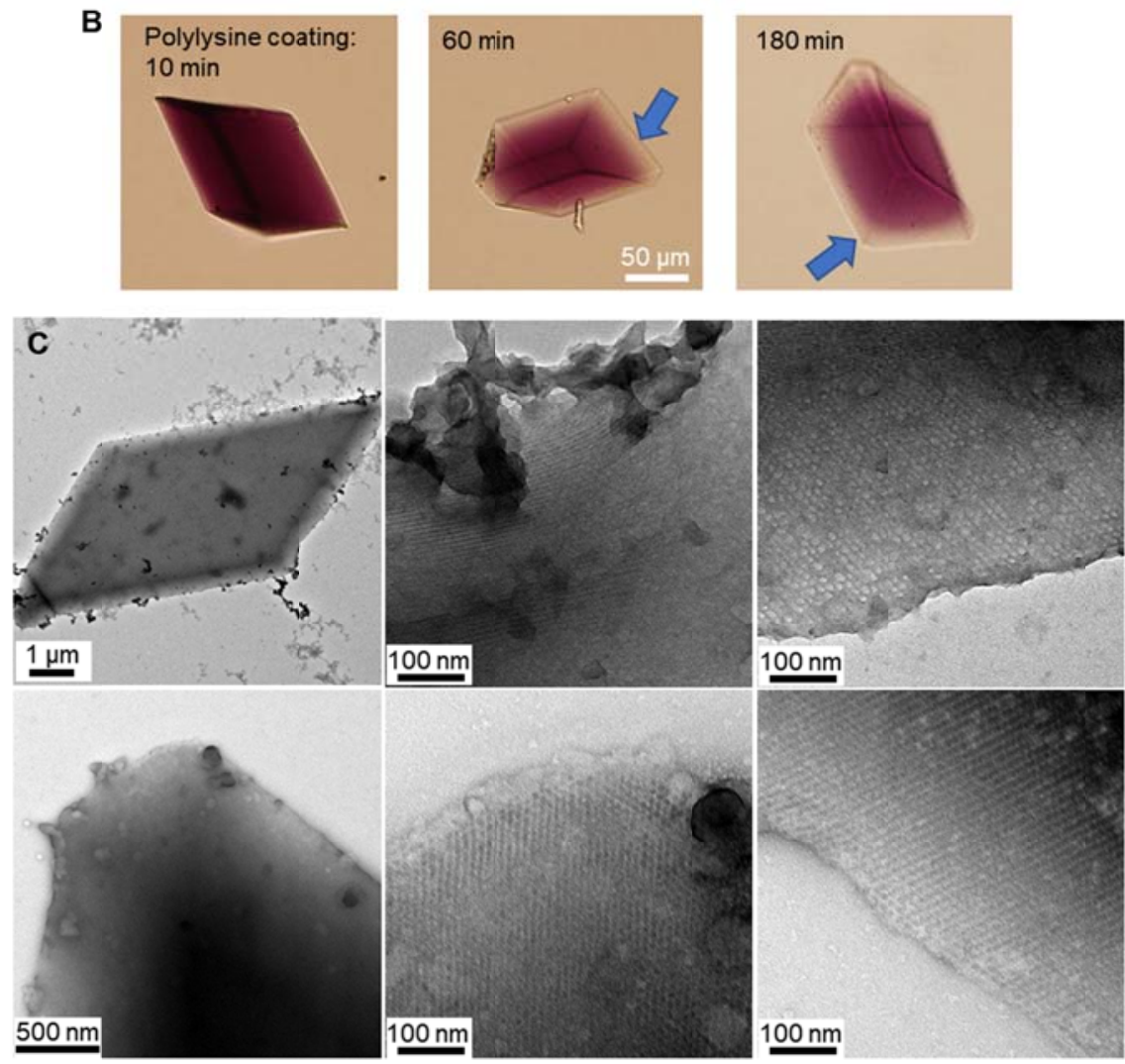


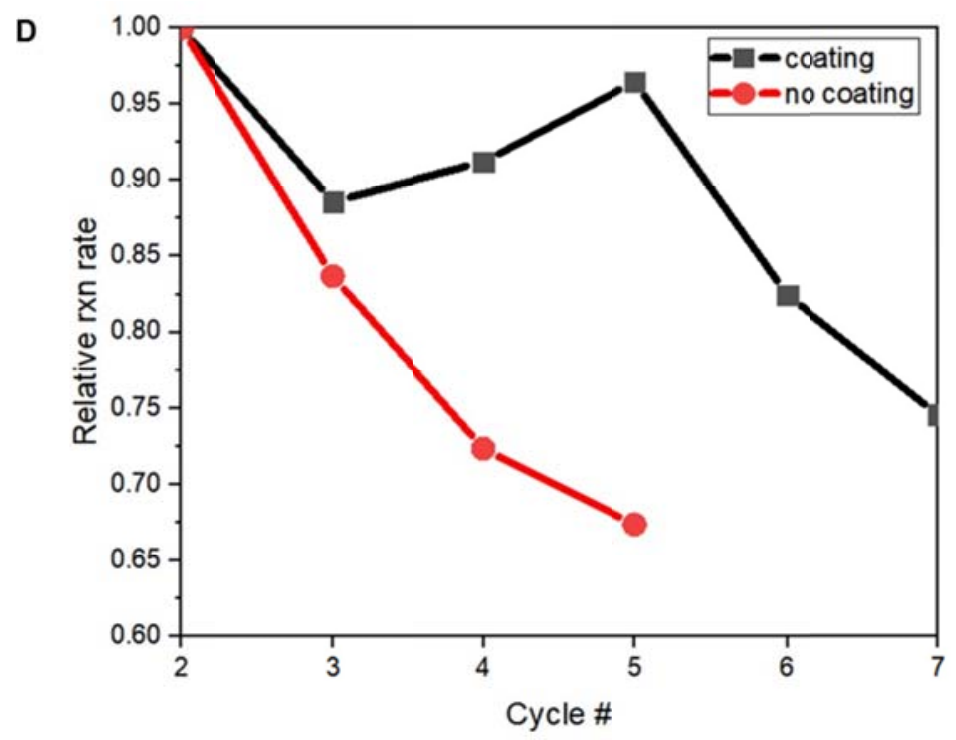

Fig. S31. Polylysine coating of HRP-immobilized $s \Delta^{4 T}$ crystals. Positively-charged polylysine was used to coat the DNA crystal surface by electrostatic adsorption. The long chains of polylysine were supposed to block the crystal pores and prevent enzyme leaking. (A) Spectrophotometer measurement of 5 cycles of reaction catalyzed by crystal catalyst without polylysine coating. Significant loss of catalysis activity can be observed in the five testing cycles, possibly due to the leaking of HRP. (B) Polylysine coatings were visually observed when the crystals were stained violet after the catalysis. The coating regions appeared transparent, possibly because polylysine disrupted the DNA structures on the crystal surface. (C) Negative-stained TEM characterization of a $\Delta^{4 \mathrm{~T}}$ microcrystals incubated in polylysine. Big chunks were observed on the surface of microcrystals. Likely, they were adsorbed polylysine. (D) Plot of relative reaction rate vs. the number of reaction cycles catalyzed by crystal-encapsulated HRP. Black: with lysine coating (data calculated from Fig. 4A); red: with lysine coating (data calculated from Fig. 31A). Relative reaction rates are calculated as the slopes in Figs. 4A and S31 and then normalized by the slopes in the corresponding $2^{\text {nd }}$ cycle of the reaction. The relative reaction rate drops much faster for the uncoated crystals than for the coated crystals, indicating polylysine coating indeed helps retaining the enzymes in the DNA crystals. 


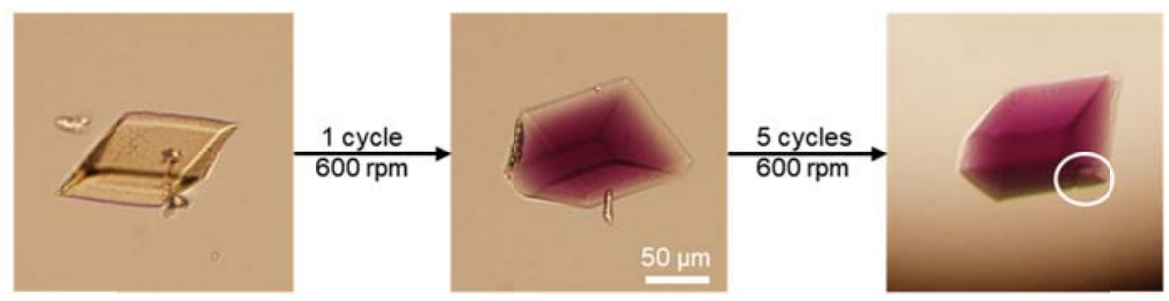

Fig. S32. Stirring during the catalysis of HRP-immobilized $s \Delta^{4 T}$ crystals. The crystal catalyst in $100 \mu \mathrm{L}$ of ABTS substrate was stirred at by a $2 \mathrm{~mm} \times 2 \mathrm{~mm}$ stir flea $600 \mathrm{rpm}$ for 5 cycles of reaction. The crystal was still intact and well-shaped after stirring. The crack in the white circle was created during handling rather than the stirring process. 


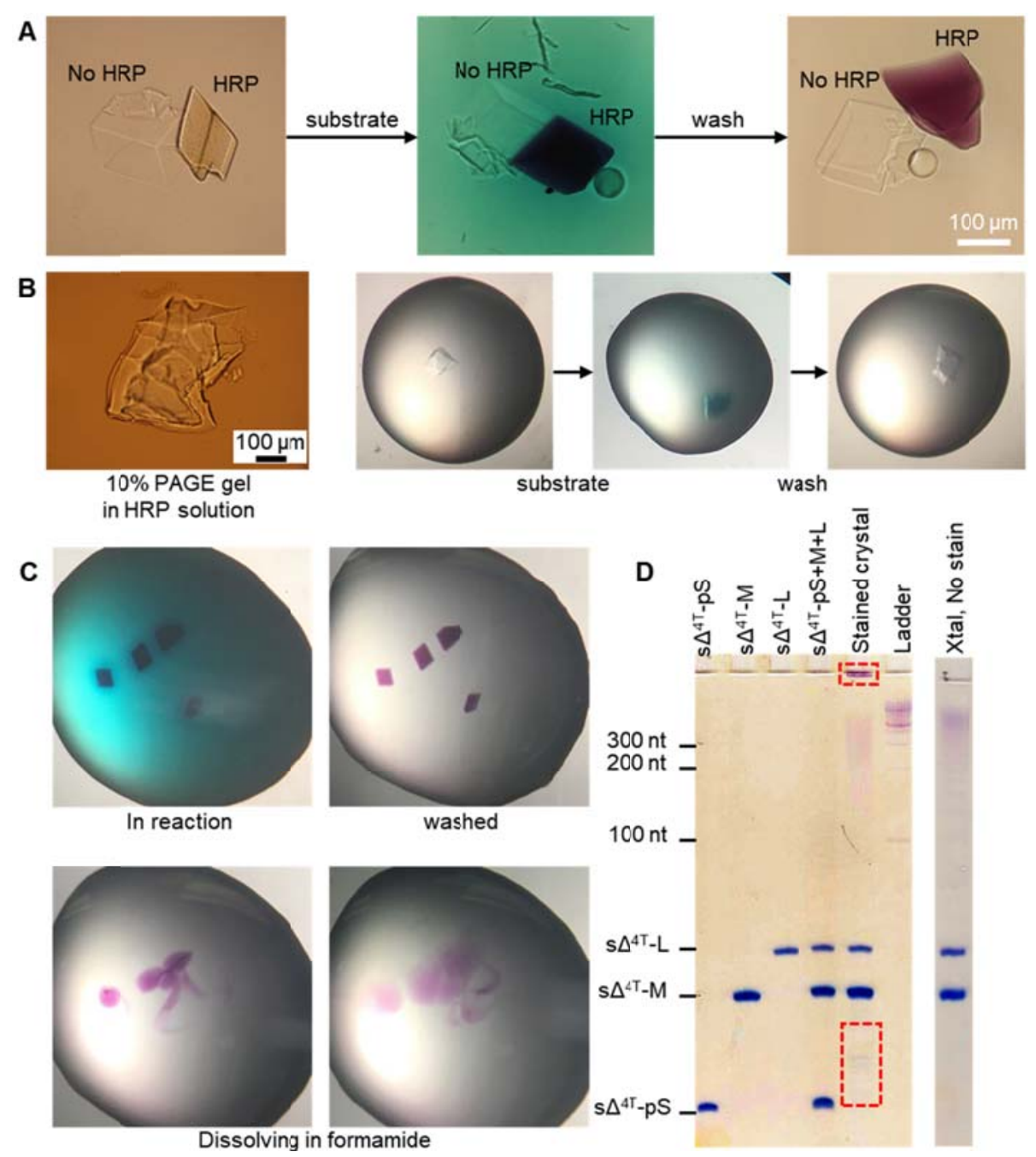

Fig. S33. Investigations for the cause for DNA $s \Delta_{4 T}$ crystal staining during catalysis. (A) Crystal with and without HRP immobilization were used for the catalysis of ABTS and $\mathrm{H}_{2} \mathrm{O}_{2}$ at the same time. Only the crystal with HRP got stained after the reaction. This shows that crystal staining requires HRP entrapment. ABTS and $\mathrm{H}_{2} \mathrm{O}_{2}$ or their reaction products cannot stain the crystal. (B) HRP immobilized in PAGE gel piece for catalysis. The PAGE gel was not stained after the reaction. This shows that crystal staining requires DNA molecules as host. (C) Analysis of stained crystals by $20 \%$ denaturing PAGE. The crystal used here only has the S strands ligated so that $\mathrm{M}$ and $\mathrm{L}$ strands will show as intense, single band in the gel for better visualization of potential band shift. The violet crystals can fully dissolve in formamide. No shift for DNA bands was observed in the gel. Extra substance was observed in the well and between $\mathrm{M}$ and $\mathrm{pS}$, as in red boxes with dashed lines. 

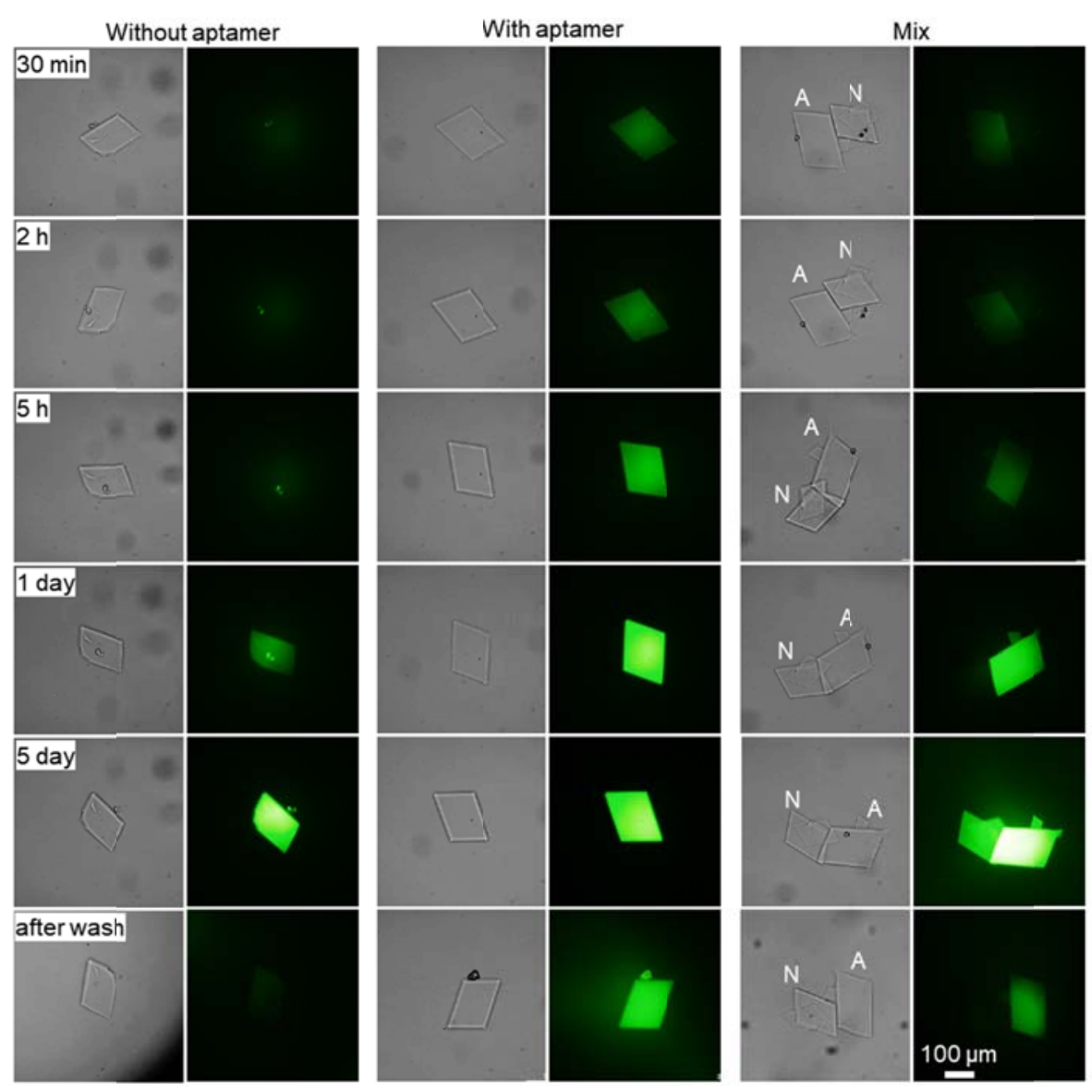

Fig. S34. Ligated DNA a $\Delta^{4 T}$ crystals with anti-His tag aptamer $6 H 7$ for entrapment of GFP with His tag. Crystals with and without aptamer $6 \mathrm{H} 7$ were incubated in His-tagged GFP in PBS buffer separately or together in the drop. Within 5 hours, crystal with aptamer (A) showed significant entrapment, while crystal without aptamer $(\mathrm{N})$ showed little entrapment. After 5 hours, nonspecific entrapment becomes more and more significant. All crystals showed good fluorescence intensity after 5 days of entrapment. After a washing step by diluting protein solution around crystals for 9 times, fluorescence went away for crystals without aptamer, while fluorescence in crystals with aptamer maintained at a relatively weaker intensity. The result demonstrated stronger entrapment with aptamer binding, as compared with nonspecific entrapment. The fluorescent images before wash were taken at 1/20 s exposure time, while the images after wash were taken at $1 / 3$ s exposure time. 

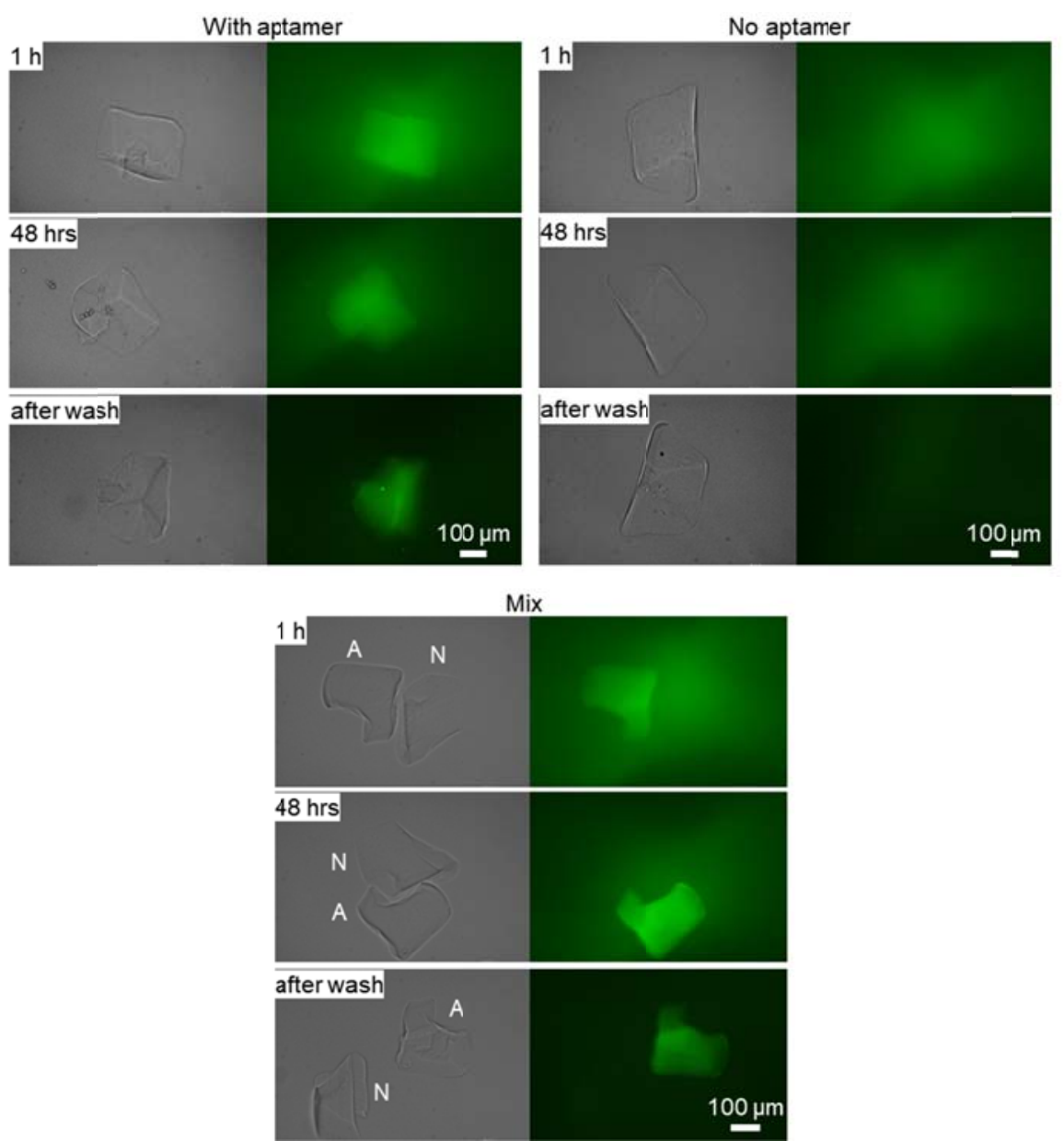

Fig. S35. Ligated DNA $s \Delta^{8 T}$ crystals with anti-His tag aptamer $6 \mathrm{H7}$ for entrapment of GFPdeaminase with His tag. Crystals with and without aptamer $6 \mathrm{H} 7$ were incubated in His-tagged GFP-deaminase in PBS buffer separately or together in the drop. After 1 hour, crystal with aptamer (A) already showed significant entrapment. Crystal without aptamer (N) showed little entrapment even after two days of incubation. After washing three times by PBS buffer, fluorescence went away for crystals without aptamer, while fluorescence in crystals with aptamer maintained at a relatively weaker intensity. The result demonstrated specific protein entrapment in crystals with aptamer. Unlike the entrapment in Fig, S36, nonspecific entrapment was not observed. The fluorescent images before wash were taken at 1/50 s exposure time, while the images after wash were taken at $1 / 5 \mathrm{~s}$ exposure time. 
A Fluorescent dye
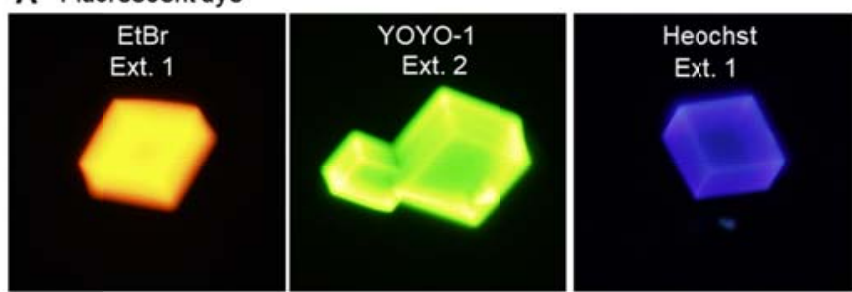

Ext. 1: $330 \sim 385 \mathrm{~nm}$
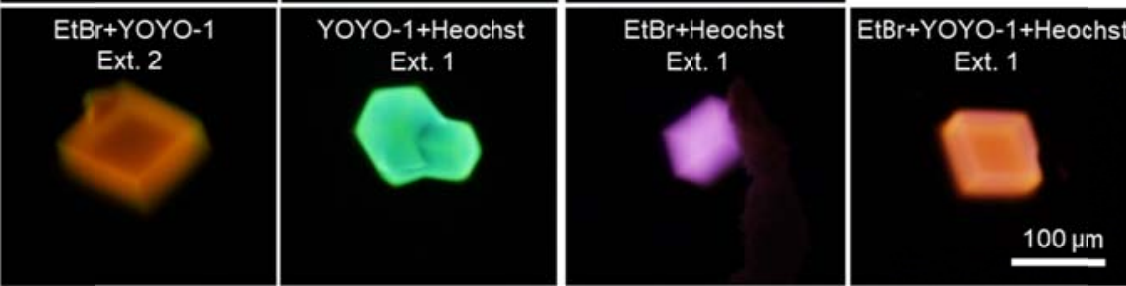

B Colorimetric dye

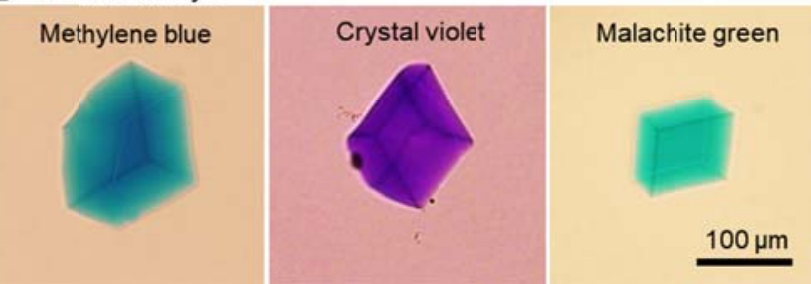

Fig. S36. Ligated DNA $s \Delta^{4 T}$ crystal stained by different dyes. (A) Fluorescent dyes and their combinations. EtBr: ethidium bromide. (B) Colorimetric dyes. 


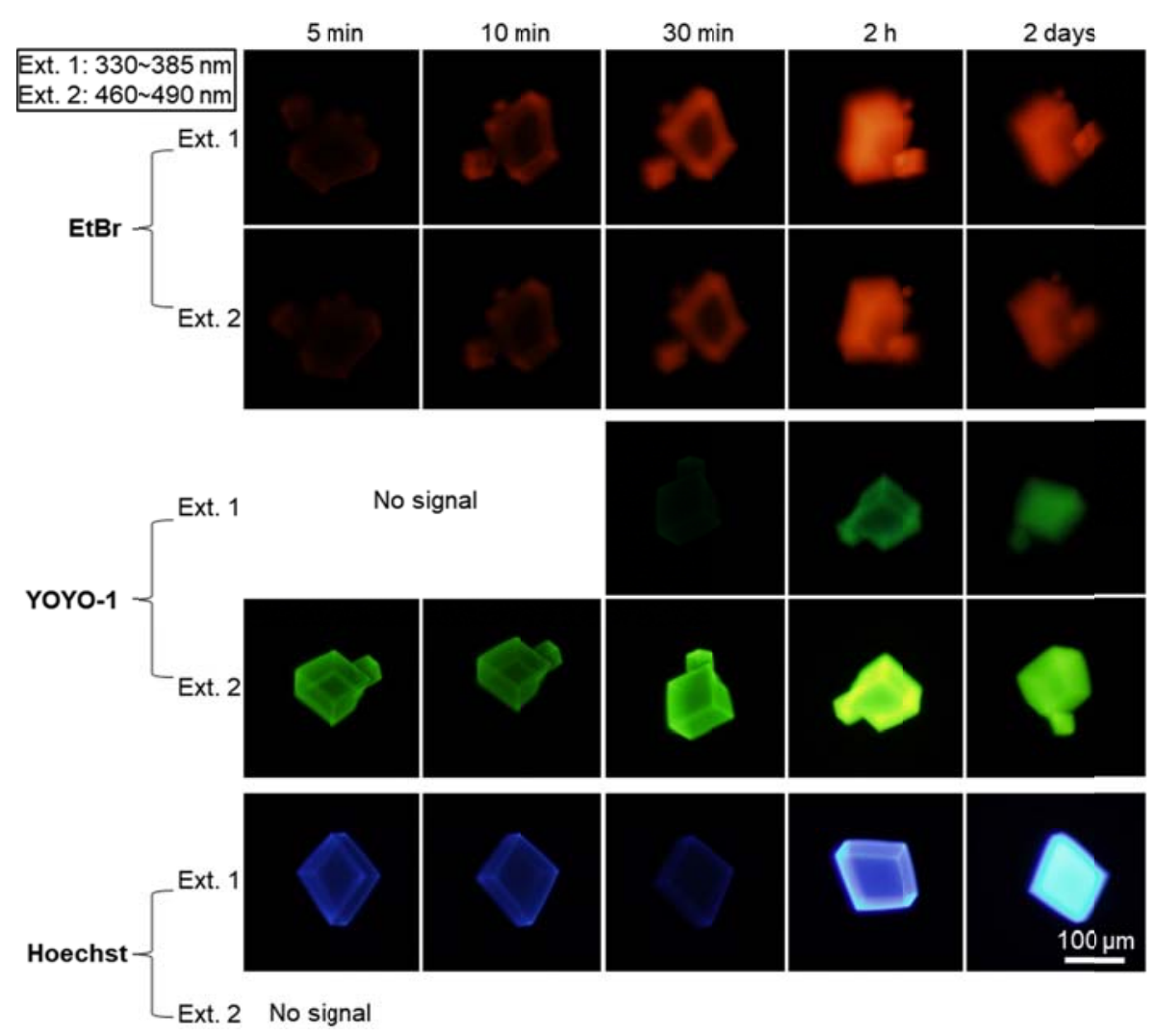

Fig. S37. Staining kinetics of ligated DNA $s \Delta^{4 T}$ crystal with fluorescent dyes EtBr, YOYO-1, and Hoechst. All dyes were of the same concentration of $\sim 0.6 \mu \mathrm{M}$ in $0.2 \times \mathrm{TAE} / \mathrm{Mg}^{2+}$. Ext.: excitation. For excitation 1, 1/100 s exposure time was used; For excitation 2, 1/1000 s exposure time was used. 


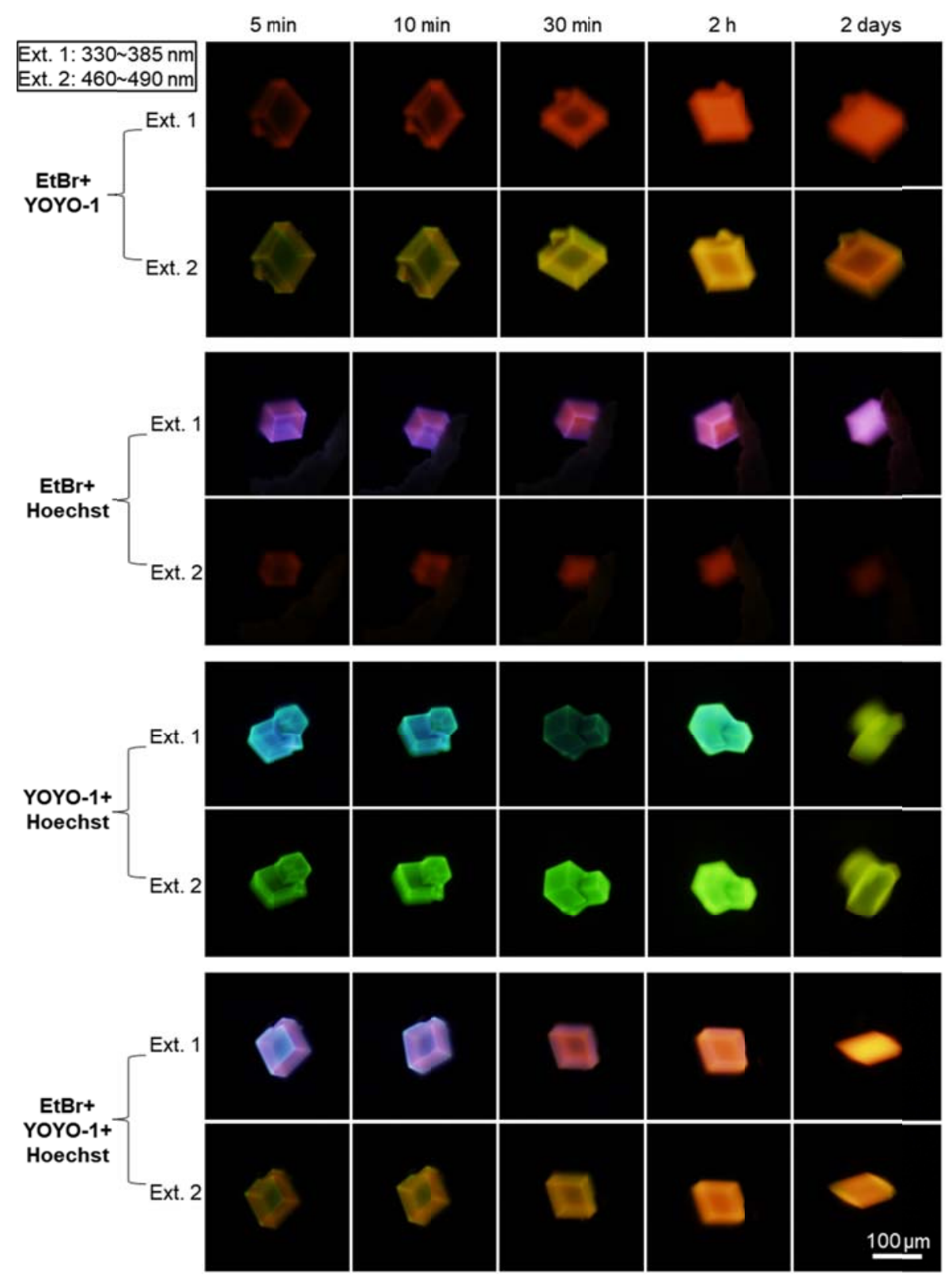

Fig. S38. Staining kinetics of ligated DNA $s \Delta^{4 \mathrm{~T}}$ crystal with multiple fluorescent dyes. $\mathrm{EtBr}$, YOYO- 1 and Hoechst were premixed in $0.2 \times \mathrm{TAE} / \mathrm{Mg}^{2+}$ at equal concentration. The mixed dyes were added to the crystal drop, with a final concentration of $\sim 0.6 \mu \mathrm{M}$ for each dye. Ext.: excitation. For excitation 1, 1/100 s exposure time was used; For excitation 2, 1/1000 s exposure time was used. 

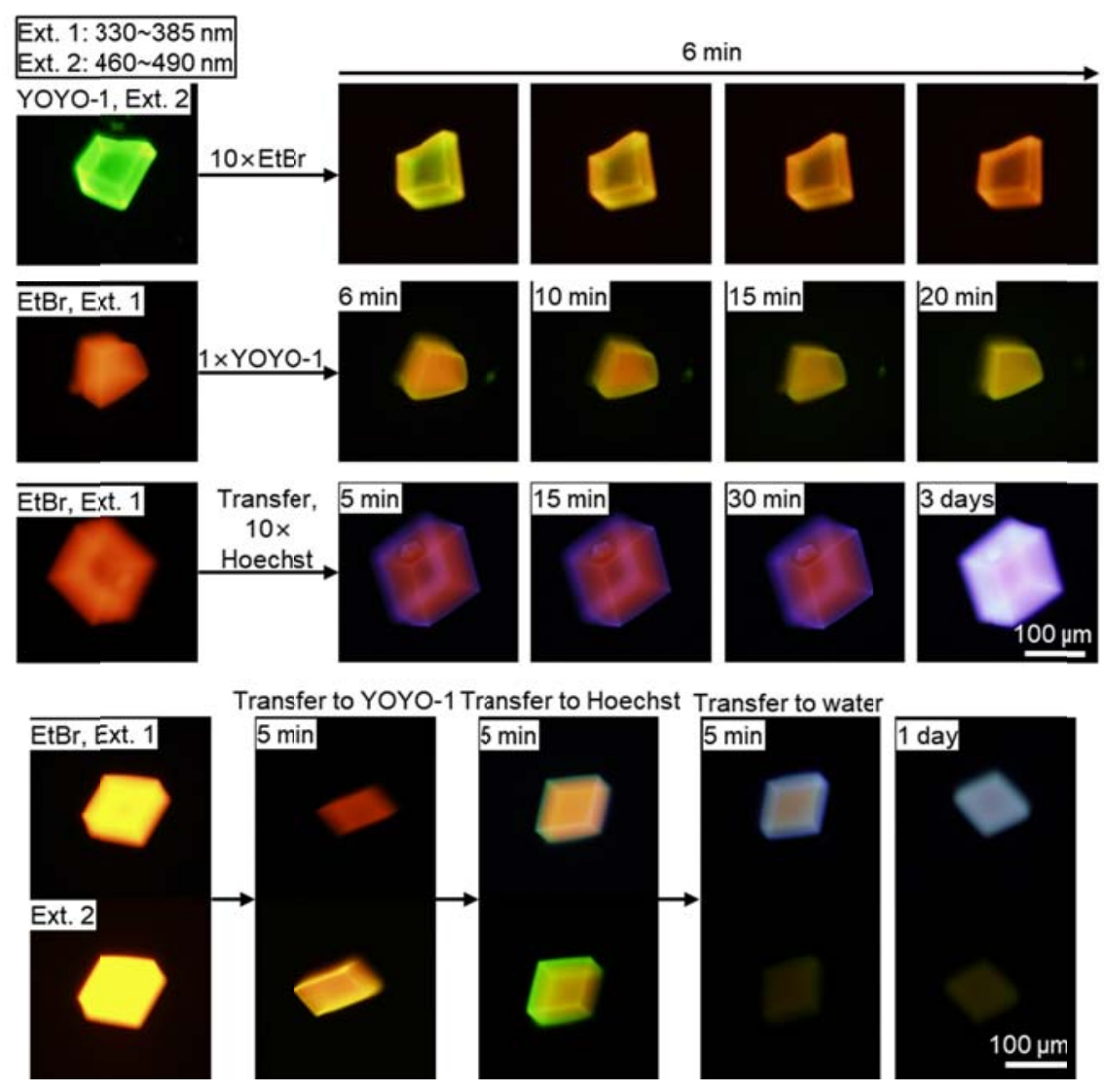

Fig. S39. Stepwise staining of ligated DNA $s \Delta^{4 T}$ crystal by different fluorescent dyes. Crystals were initially stained by fluorescent dyes of $\sim 0.6 \mu \mathrm{M}$ in $0.2 \times \mathrm{TAE} / \mathrm{Mg}^{2+}$ for more than 10 mins. $1 \times$ and $10 \times$ concentrations correspond to $0.6 \mu \mathrm{M}$ and $6 \mu \mathrm{M}$ dye in the final drop. In the top two samples, the $2^{\text {nd }}$ dye was added directly to the drop, with the $1^{\text {st }}$ dye still present. For the bottom two samples, crystals were transferred to new drops of the $2^{\text {nd }}$ fluorescent dye, with minimal amount of the $1^{\text {st }}$ dye in solution. During the time-lapse imaging of the same sample, the exposure time was set unchanged. For different samples, exposure time was manually adjusted for optimal observation. 